\title{
Assessments of available riverine hydrokinetic energy: a review
}

\author{
Katelyn Kirby, Sean Ferguson, Colin Rennie, Ioan Nistor, and Julien Cousineau
}

\begin{abstract}
Methods of estimating riverine hydrokinetic (HK) power for localized and regional studies are reviewed, evaluated, and compared. It was found that localized HK studies were not entirely consistent, with the most common discrepancies being discharge variability characterization, uncertainty analysis, and the amount of data used to derive the results. The issues associated with localized assessments were amplified for regional assessments. Regional HK assessments were less common, the methods were less consistent across studies, and the amount and type of data available varied widely across regions. New techniques and technologies, developed in Canada and globally, were evaluated for their usefulness to improve regional HK assessments. Emphasis was put on satellite remote sensing methods to estimate discharge and channel dimensions, as well as regionalized curve fitting to estimate channel roughness. The review of new techniques suggests that accuracy of the results is dependent on the amount and quality of the data available.
\end{abstract}

Key words: satellite remote sensing, resource assessment, river hydraulics, hydrology regionalization, bathymetry estimation.

Résumé : Les méthodes d'estimation de la puissance hydrocinétique (HC) fluviale pour les études localisées et régionales sont examinées, évaluées et comparées. On a constaté que les études localisées de l'HC n'étaient pas entièrement cohérentes, les écarts les plus courants étant la caractérisation de la variabilité du débit, l'analyse de l'incertitude et la quantité de données utilisées pour obtenir les résultats. Les problèmes associés aux évaluations localisées ont été amplifiés dans le cas des évaluations régionales. Les évaluations régionales de l'HC étaient moins fréquentes, les méthodes étaient moins cohérentes entre les études, et la quantité et le type de données disponibles variaient considérablement d'une région à l'autre. Les nouvelles techniques et technologies mises au point au Canada et à l'échelle mondiale ont été évaluées pour leur utilité afin d'améliorer les évaluations régionales de l'HC. L’accent a été mis sur les méthodes de télédétection par satellite pour estimer les dimensions du chenal et les débits, ainsi que sur l'ajustement des courbes régionalisées pour estimer la rugosité du chenal. L'examen des nouvelles techniques suggère que l'exactitude des résultats dépend de la quantité et de la qualité des données disponibles. [Traduit par la Rédaction]

Mots-clés : télédétection par satellite, évaluation des ressources, hydraulique fluviale, régionalisation de l'hydrologie, estimation bathymétrique.

\section{Introduction}

The extraction of hydrokinetic (HK) power involves utilizing tidal or wave energy of the ocean or velocity energy of a river to turn a turbine to generate electricity. HK technology is referred to as "run-of-river", because it does not greatly impact the discharge of the river, as compared to conventional hydroelectric dams, which alter a river's natural discharge and bathymetry. However, the caveat of HK power is that it is reliant on the conditions of the river environment that it is introduced into. This includes seasonal discharge variation, depth and width limitations, accessibility issues, and even blockages due to vegetation, large woody debris, or ice. Additionally, HK power is not as efficient as conventional hydropower with an efficiency limit of 59.3\%, defined as the Betz limit (Yuce and Muratoglu 2015). HK energy may provide a promising alternative to conventional electricity generation in Canada and globally, and thus it has been gaining attention over the past two decades. Particularly in Canada, emphasis has been put upon exploring power generation methods that do not create greenhouse gases (GHGs), which are the leading cause of global climate change. Canada entered the Paris agreement in an attempt to keep the earth's temperature rise under $2{ }^{\circ} \mathrm{C}$ due to global climate change (Environment and Climate Change Canada 2016). To do this, Canada pledged to transition to $90 \%$ nonGHG-emitting electricity by 2030 (Government of Canada 2019). Another initiative that Canada has created is the Off-Diesel Challenge from the Clean Energy for Rural and Remote Communities program by Natural Resources Canada, which aims to reduce reliance on diesel fuel for rural and remote communities (Natural Resources Canada 2019). Other notable initiatives are the Low Carbon Economy Fund (Government of Canada 2020b), the Clean Growth Hub (Government of Canada 2020a), and the Powering Past Coal Alliance (Government of Canada 2019). Other countries around the globe have such initiatives as well. To bolster this increased interest in non-GHG-emitting electricity sources, HK energy potential should be thoroughly explored to understand if

Received 8 April 2021. Accepted 27 August 2021.

K. Kirby. Faculty of Environmental Engineering, University of Ottawa, 75 Laurier Ave. E, Ottawa, ON K1N 6N5, Canada.

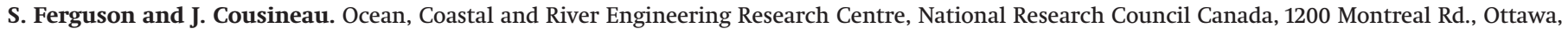
ON K1A 0R6, Canada.

C. Rennie and I. Nistor.* Faculty of Civil Engineering, University of Ottawa, 75 Laurier Ave. E, Ottawa, ON K1N 6N5, Canada.

Correspondence author: Katelyn Kirby (email: kkirb087@uottawa.ca).

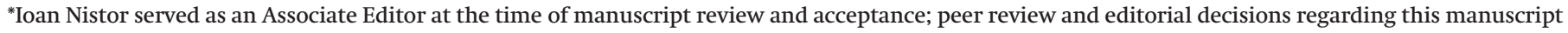
were handled by another Editorial Board Member.

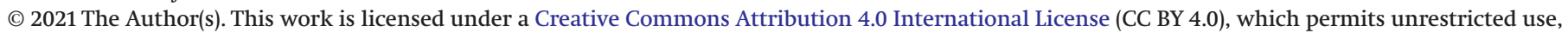
distribution, and reproduction in any medium, provided the original author(s) and source are credited. 
it is a feasible alternative, and, if so, where would it be most suitable. This review only covers riverine HK potential.

To understand if HK power is feasible, local and regional studies have been conducted in various areas across the globe to quantify the amount of HK potential in rivers. Regional types of studies are usually completed on the national or provincial/state scale. Their intents are to locate areas of high HK potential to further investigate on a smaller or local scale, to quantify the total possible amount of HK energy to decide if investment is wise, and to make the information readily available for potential investors. Some common factors that may be barriers to a feasible HK installation in an area are depth limitations (usually not feasible for less than $2 \mathrm{~m}$ ) preventing the physical installation of a turbine unit or array, low velocity (approximately less than $1.5 \mathrm{~m} / \mathrm{s}$ ) indicating that there is low power extraction potential and poor return on investment, and other technical, societal, environmental, and economic considerations that will not be discussed in this paper. The cost of in-depth, site-specific hydrologic studies can be restrictive, as most local hydro developments cannot afford these types of studies; therefore, regional HK assessments are employed to evaluate if a location may be profitable before significant investment is made (Judge et al. 1988). The objectives of this review are to understand where HK resource assessment research is at and how it has evolved, to evaluate possible areas of improvement or advancements in HK power estimation (i.e., new technology or tools available), and to draw conclusions about research gaps and methodological requirements in HK assessments. To this end, this study will evaluate both local (i.e., single location or single reach) and regional (i.e., regional, provincial, or national) HK assessments in Canada and globally to understand the methods that currently exist, to explore new technologies or advancements that may improve the assessments previously evaluated, and finally to make recommendations on further research based on its findings.

\section{Local hydrokinetic energy resource assessments}

To begin, the methods of local HK potential assessments will be evaluated, because these types of assessments are more numerous, and they have been conducted more recently compared to regional assessments (Table 1). Therefore, they will provide more insight into the current state of HK assessments. Also, they will provide an idea of the limitations that arise when attempting to duplicate local HK assessment methods on a regional scale. Local HK assessments refer to either single deployment location, single reach with multiple deployment locations, or multiple (two or three) reach assessments. In general, because the size of the study area is small for local assessments, more effort is placed into ensuring high quality data are available to begin the assessment (e.g., spatially intense field data, LiDAR or other high-resolution imagery, etc.), and this contributes to more accurate results. One of the aims in assessing these local studies, separately from regional studies, is to understand if and how the methods can be applied to regional assessments and to define the limitations of assessments at the local scale. More local assessments exist, and it is more state-of-the-art than regional assessments (i.e., the most recent local studies are 2011 to 2020 compared to 1984 to 2020 for regional). As such, it was useful to evaluate local studies first separately to understand the methods used and if those methods were scalable. In tandem with this objective, the state-of-the-art in local HK resource assessments will be explored and any caveats to the methods will be discussed.

The International Electrotechnical Commission (IEC) published standards for local HK assessments under technical specification 62600-301 Marine Energy - Wave, Tidal and Other Water Current Converters, Part 301: River Energy Resource Assessment in 2019. This document will be evaluated first in this review paper because it is the most comprehensive, and all other studies will be compared to its methodologies. Essentially, the specification provides required steps and suggested methods to process available gauged data and (or) field data into an estimate of riverine HK potential. It provides other requirements on top of the methodological requirements, such as documentation, model calibration, result validation, and acceptable model error. Overall, the goal is to generate a velocity duration curve (VDC), from which the potential HK power, or annual energy production (AEP), can be calculated. The first step is to generate a 15-point flow duration curve (FDC), as this will account for the empirical variation of the river discharge. The FDC can be generated from ten years of discharge data for the location if available. If ten years of data are not available, a hydrological model should be employed to generate ten years of synthetic discharge data. That generated data should be validated with one year of available discharge data for the location. Therefore, as per the IEC standards, at least one year of discharge data are required for any potential HK development location. The next step is to create a curve fit for the velocity-discharge measurement, and this step also depends on the amount of data readily available for the location. VDCs can be developed directly at locations with 5 velocitydischarge measurements at the specific renewable energy convertor (REC) location (i.e., at the particular location within the cross section of the channel) for "small" projects. The IEC defines a small project as projects which have a project blockage ratio (ratio of moving and non-moving area of all RECs to average channel crosssectional area) of less than 5\%, projects in which each REC has at least ten equivalent diameters spacing from each other. This also includes projects that have not introduced any flow modification to increase the available power. If there are not five velocitydischarge measurements available for the REC location or if the project is "large" (any projects which do not meet the small project requirements), a model shall be used to estimate this relationship. To be able to use a model, three different stage-discharge conditions are needed for the model input, two channel transects of velocity for three different discharge conditions are needed for the model calibration, and velocity-discharge measurements at two REC locations for three different discharge conditions are needed for verification. The IEC standards reference the International Hydrographic Organization's Standards for Hydrographic Surveys for information on how to properly collect field data (IHO 2020). The standards also indicate that the effects of the turbine being introduced into the river need to be considered and estimated for projects deemed to be large. When the velocity data are available, either from modelling or measurements, a curve should be fit to the velocity-discharge relationship for each REC location within the river. From that, the VDC can be generated, and the AEP can be calculated for each REC. The document describes types of models that can be used for the assessments and their calibration and validation requirements, as well as the benefits or drawbacks of each type of model. Overall, the standards leave the choice of model to be used up to the team conducting the study, as long as the model meets the accuracy requirements of the HK assessment. The assessment can either be based on an REC with known parameters (i.e., provided by a manufacturer) or from a generic REC with generic parameters. When comparing the output of the model to measurements, the relative mean squared difference between the two should not be greater than 10\% (IEC 2019).

Neary et al. (2011) developed a best practice manual for the collection of field measurement data required for the assessment of potential $\mathrm{HK}$ at identified deployment sites. The document was published by the Oak Ridge National Laboratory. The purpose of the guideline was to increase accuracy of HK assessments with the goal of comparison to conventional electricity generation and other renewables. When the document was published in 2011, assessments of the time had power densities averaged over grid cells of $300 \mathrm{~m}$ to $500 \mathrm{~m}$ resolution. Neary et al. (2011) argued that models needed to be more refined, such as those created with spatially intense field data using ADCP, ADV, or other such measuring device, for development to take place. The complexities of estimating HK power in a stream were recognized by Neary et al. (2011), 
Table 1. Local hydrokinetic energy resource assessments.

\begin{tabular}{|c|c|c|c|c|c|c|}
\hline Study \# & Authors & $\begin{array}{l}\text { Assessment } \\
\text { approach }\end{array}$ & $\begin{array}{l}\text { Flow variation } \\
\text { consideration }\end{array}$ & $\begin{array}{l}\text { Estimation } \\
\text { method(s) }\end{array}$ & $\begin{array}{l}\text { Error analysis } \\
\text { method(s) }\end{array}$ & $\begin{array}{l}\text { Quantified error } \\
\text { result(s) }\end{array}$ \\
\hline Standard & IEC (2019) & Hydrokinetic & 15-point FDC and VDC & $\begin{array}{l}\text { VDC and AEP estimation via } \\
\text { 15-point FDC based on } \\
10 \text { years of available or } \\
\text { synthetic, modelled } \\
\text { discharge data }\end{array}$ & $\begin{array}{l}\text { Model calibration using } \\
\text { agreement between depth- } \\
\text { averaged velocity and } \\
\text { validation using agreement } \\
\text { between depth-averaged } \\
\text { velocity and vertical velocity } \\
\text { variation }\end{array}$ & $\begin{array}{l}5 \% \text { or less for calibration } \\
\text { and } 10 \% \text { or less for } \\
\text { depth-averaged velocity } \\
\text { validation and } 25 \% \text { or } \\
\text { less for vertical velocity } \\
\text { validation }\end{array}$ \\
\hline 1) & Arango (2011) & Hydrokinetic & $\begin{array}{l}5 \text { percentile, } \\
50 \text { percentile, and } \\
95 \text { percentile }\end{array}$ & $\begin{array}{l}\text { Cumulative probability } \\
\text { distribution functions of } \\
\text { discharge and physical and } \\
\text { computational fluid } \\
\text { dynamic models }\end{array}$ & None & None \\
\hline 2) & Duvoy and Toniolo (2012) & Hydrokinetic & Not considered & $\begin{array}{l}\text { Hydrodynamic model using } \\
\text { data collected in field } \\
\text { campaign }\end{array}$ & None & None \\
\hline 3) & Petrie et al. (2014) & Hydrokinetic & Not considered & $\begin{array}{l}\text { Velocity data collected in } \\
\text { field campaign }\end{array}$ & $\begin{array}{l}\text { Data expected to contain error } \\
\text { over threshold limit was } \\
\text { discarded }\end{array}$ & None \\
\hline 4) & Kalnacs et al. (2014) & Hydrokinetic & Not considered & $\begin{array}{l}\text { Velocity data collected in } \\
\text { field campaign }\end{array}$ & $\begin{array}{l}\text { Visual comparison between } \\
\text { collected data and available } \\
\text { statistical data }\end{array}$ & None \\
\hline 5) & Punys et al. (2015) & Hydrokinetic & $\begin{array}{l}\text { Mean annual, bankfull, } \\
\text { and low discharge }\end{array}$ & $\begin{array}{l}\text { HEC-RAS hydraulic model to } \\
\text { estimate discharge, channel } \\
\text { geometry, and velocity } \\
\text { using historical data }\end{array}$ & $\begin{array}{l}\text { Visual comparison between } \\
\text { hydraulic model parameters } \\
\text { and hydrologic model } \\
\text { parameters }\end{array}$ & None \\
\hline 6) & Cornett and Faure (2015) & Hydrokinetic & $\begin{array}{l}\text { Variation over a typical } \\
\text { year }\end{array}$ & $\begin{array}{l}\text { Hydrograph estimation and } \\
\text { TELEMAC-2D hydrodynamic } \\
\text { model using historical data }\end{array}$ & $\begin{array}{l}\text { Validation using historical } \\
\text { discharge and water level for } \\
\text { several gauging stations }\end{array}$ & No information available \\
\hline 7) & Filizola et al. (2015) & Hydrokinetic & Not considered & $\begin{array}{l}\text { Velocity flow field data used } \\
\text { to calculate theoretical } \\
\text { hydrokinetic power }\end{array}$ & None & None \\
\hline 8) & $\begin{array}{l}\text { Montoya Ramírez, et al. } \\
\text { (2016) }\end{array}$ & Hydrokinetic & $\begin{array}{l}\text { Joint probability curves } \\
\text { and duration curves } \\
\text { using } 100 \mathrm{~h} \text { of data }\end{array}$ & $\begin{array}{l}\text { HEC-RAS hydraulic model } \\
\text { with hourly discharge data } \\
\text { to simulate mean velocity }\end{array}$ & None & None \\
\hline 9) & Nordino (2016) & Hydrokinetic & $\begin{array}{l}\text { VDC from five years of } \\
\text { historical data }\end{array}$ & $\begin{array}{l}\text { VDC generation from } \\
\text { historical data }\end{array}$ & None & None \\
\hline 10) & Nhabetse et al. (2017) & Hydrokinetic & $\begin{array}{l}\text { VDC from five years of } \\
\text { historical data }\end{array}$ & $\begin{array}{l}\text { VDC generation from } \\
\text { historical data }\end{array}$ & None & None \\
\hline 11) & Holanda et al. (2017) & Hydrokinetic & $\begin{array}{l}\text { Maximum, minimum, } \\
\text { and mean discharge }\end{array}$ & $\begin{array}{l}\text { Hydrodynamic model to } \\
\text { simulate velocity }\end{array}$ & $\begin{array}{l}\text { Validation against field } \\
\text { measurements using average } \\
\text { error }\end{array}$ & $\begin{array}{l}\text { Average error of } 8.77 \% \\
\text { and maximum error of } \\
22.00 \% \text { in simulated } \\
\text { velocity }\end{array}$ \\
\hline 12) & Saupi et al. (2018) & Hydrokinetic & $\begin{array}{l}120 \text { days of data used to } \\
\text { develop regression }\end{array}$ & Best fit regression equations & $\begin{array}{l}\text { Validation against field } \\
\text { measurements using } R^{2}\end{array}$ & $\begin{array}{l}R^{2} \text { of } 87.4 \% \text { and } 87.9 \% \text { for } \\
\text { water level and velocity, } \\
\text { respectively }\end{array}$ \\
\hline
\end{tabular}




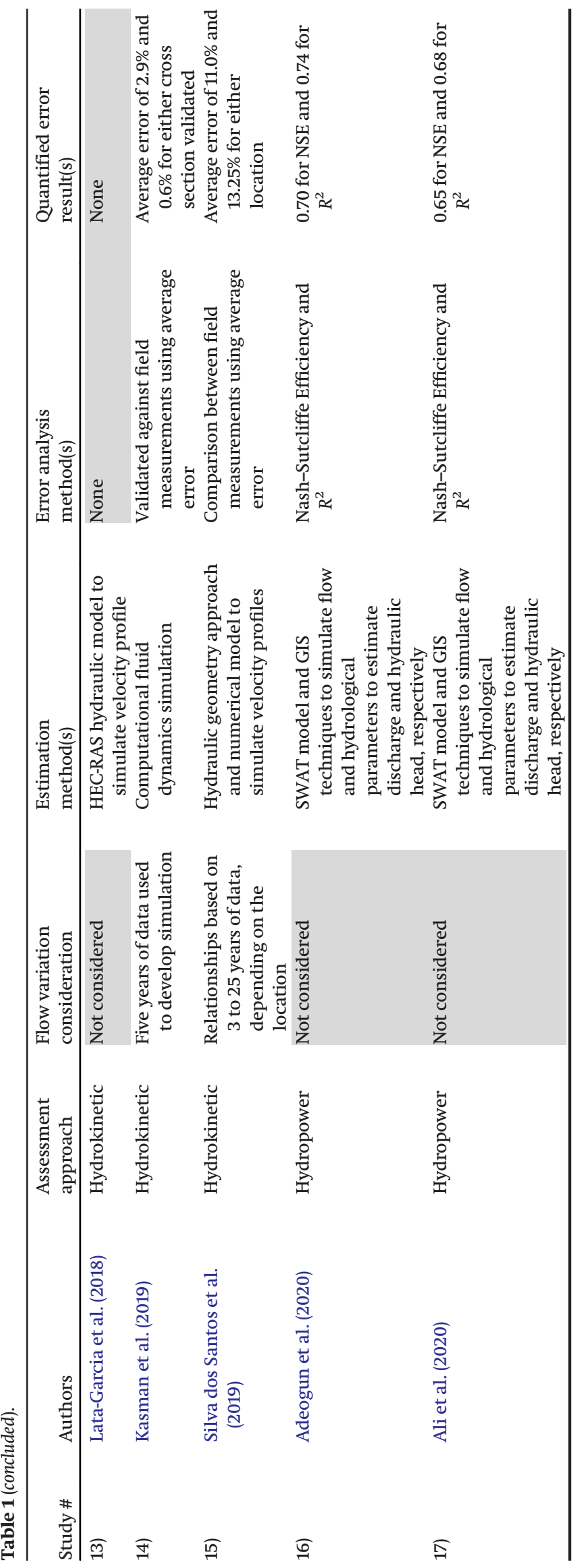

as it was mentioned that the following variables could change conditions along the length of the river reach: bed sediment, grain, and form roughness; secondary circulation caused by channel form; wind shear on the water surface; and the presence of structures that could create surface wakes, vortex shedding, and increased turbulence in the wake. Therefore, various measurements are required to properly characterize the complexities of velocity in the reach, which include reach bathymetry, bed substrates, in-stream flow structures, properties of the fluid, and flow field. For reach bathymetry, Neary et al. (2011) recommends the use of single and multi-beam depth echosounders (SBE, MBE) coupled with GPS. Particularly, it is important to capture the bed form at the location of interest, such as the wavelength and height of dunes, ripples, or antidunes. For bed substrate, samples should be taken at the location of interest to characterize the particle size, specific gravity, shape factor, and fall size of the bed and bank materials. To properly model the effect of in-stream structures on the AEP available and the effects of introducing a turbine into the river environment, measurements of the structures present should be available. Properties of the fluid that should be measured are temperature, density, kinematic viscosity, and salinity. The turbidity of the fluid can cause changes to the flow field, so it should be measured as well. Finally, one should attempt to understand the turbulence and how it effects the flow field velocity. In general, the flow field velocity is time averaged because of temporal variability induced by turbulence effects (Neary et al. 2011).

Local studies are reviewed to evaluate their methodology and their conformance to the previously reviewed standards and guidelines of HK assessments. Also, reviewing local studies will provide insight to the limitations of regional studies and may suggest possible techniques of overcoming these limitations. Arango (2011) conducted a study of four potential identified HK extraction sites on the Columbia River downstream of Wanapum and Priest Rapids Dams, both at channel constrictions. 15 years of discharge information were provided in the Columbia River Data Access data bank and from Grant PUD operational records. Cumulative probability functions were generated from the available discharge data. Bathymetry data at each dam tailrace were available via field measurements from the Iowa Institute of Hydraulic Research (IIHR). The vertical velocity profile and bathymetry data used in the study were simulated by physical and computation fluid dynamic models of the two dam tailraces. The modelled data were developed and provided by the IIHR. Time-averaged, three-dimensional velocity profiles were generated for low, mean, and high discharge conditions ( $5 \%$ percentile, $50 \%$ percentile, and $95 \%$ percentile, respectively) at each channel transect. HK power density was calculated through the water column at each site using the simulated velocity profiles, discharge probability distribution, and the parameters of the turbines under consideration. Arango (2011) mentioned that there is not sufficient information provided by the IIHR to validate the data provided by the IIHR models. As such, the error in the data utilized in the study and final results were not quantified (Arango 2011).

Duvoy and Toniolo (2012) studied the HK potential at a location on the Tanana River at Nenana, Alaska. Discharge data were obtained from a United States Geological Survey (USGS) gauging station in the area and bathymetric surveys were conducted on August 8, 9, 12, and 13, 2010. During the bathymetric survey campaign, acoustic doppler current profiler (ADCP) measurements were taken for velocity profiles and slope data were collected. This study employed HYDROKAL, an external module for the CCHE2D hydrodynamic model which utilizes velocity estimates from CCHE2D to calculate instantaneous power density in the channel. Seasonal variation of the discharge was not considered in this study, as the stream power was only simulated for the duration of the field data collection. Although Duvoy and Toniolo (2012) stated that the purpose of the study was to test the capabilities of the HYDROKAL model rather than to conduct a full HK 
assessment study to estimate the AEP, it is useful to review the inputs that were needed for the hydrokinetic energy assessment model and the caveats of the research. For validation of the model's velocity estimates, the model output was compared to ADCP measurements visually. The visual comparison showed good correlation between the model output and the measured velocity. Because the model output is averaged in the vertical direction and the ADCP provides vertical velocity profiles along the transect, Duvoy and Toniolo (2012) argued that strict validation of the results was not possible.

Petrie et al. (2014) utilized ADCP measurements to identify locations within a reach with fast-moving water and thus high HK energy potential. The ADCP data used in the study were collected on two cross sections of the lower Roanoke River, USA and was processed to extract channel depth, depth-averaged velocity, flow direction, and mean three-dimensional velocity profiles. The data was collected at each location within the reach for a minimum of $1200 \mathrm{~s}$ at a single discharge condition. As such, the influence of the discharge condition on the velocity flow field and the associated locations with high HK energy potential was not considered in this study. The error associated with the ADCP measurements was not addressed in this study; however, the authors comment on directional errors that were observed in the measurements close to the riverbank. As such, measurements that were expected to contain error over a specified threshold were automatically removed from the record to reduce overall inaccuracy in the results (Petrie et al. 2014).

A study conducted by Kalnacs et al. (2014) used direct in-river velocity measurements to investigate optimal locations for turbine deployment within Daugava River, Latvia. The researchers referred to Chapter 6 of the Manual on Stream Gauging (World Meteorological Organization 2010) for field measurement procedures, but it is not clear what equipment the velocity measurements were taken with. The validation of the velocity field data was completed by visually comparing the available statistical data from the Latvia Statefinanced observation station network against the measured data's calculated flow rate. Kalnacs et al. (2014) state that the results of the comparison imply that the measured data comply and could be used to calculate estimates of HK power in the reach.

Punys et al. (2015) conducted a study of the Neris River in Lithuania where between 9 and 52 years of gauging station discharge data were available, depending on the study area. Stage, velocity, and cross-sectional area data were also available at these gauged locations. From these data, discharge-stage, discharge-velocity, and discharge-area relationships were developed as the hydrological models for the study area. The HEC-RAS hydraulic model was used to simulate mean annual, bankfull, and low discharges from which velocity, bathymetry, and stream power were also estimated. The model was calibrated using field measurements at 27 sites along the river, from the mouth to the border of Lithuania. Validation of the model was completed with stage, velocity, discharge, and cross-sectional area data from three gauging stations. The resulting simulated velocity was used to calculate $\mathrm{HK}$ power density in three discharge conditions. The parameters generated by the hydraulic model were compared to those provided by the hydrologic model and good correlation in the stage datasets were observed. However, scattering was present when visually comparing the velocities and cross-sectional area plots.

Cornett and Faure (2015) conducted a study on the St. Lawrence River at two locations: the first one between Cornwall and Montreal $(80 \mathrm{~km}$ long reach) and the second one downstream of Montreal from Sorel into the Gulf of St. Lawrence ( $800 \mathrm{~km}$ long reach). The second location presented a challenge, as flow is both tidal and fluvial. Historical discharge information was used to develop a hydrograph, and bathymetry data were obtained from the Meteorological Services Branch of Environment Canada as well as additional survey data from the Seaway International Bridge Corporation and Verdant Power Canada. TELEMAC-2D was the model used to simulate variation in discharge and water level over a typical year by solving the vertically averaged shallow water equations (i.e., Saint-Venant) in two dimensions. The available HK power was calculated from the simulated velocity values. The model was validated using historical discharge values and water levels (Cornett and Faure 2015).

Filizola et al. (2015) estimated the HK potential at eight locations in the Brazilian Amazon River Basin. Originally, 54 sites were considered in the analysis; however, with data availability and desirable hydrological characteristic constraints applied, only eight were suitable for further analysis. Data availability included velocity flow fields which were measured with $\mathrm{ADCP}$ apart from this study. The velocity flow fields were used to determine the optimum location within the reach for HK energy extraction as well as calculation of the extractable HK energy. The available extractable area for each river cross section was assumed to be $1000 \mathrm{~m}^{3}$. No error analysis was conducted on the ADCP data used in the evaluation (Filizola et al. 2015).

Montoya Ramírez et al. (2016) studied the feasibility of deploying HK turbines in the tailrace of dams at two hydropower plant locations in Columbia. To obtain time series of mean flow velocity, stream velocity, and water depth, the non-stationary onedimensional HEC-RAS hydraulic model Version 4.1 was used with hourly flow discharge input data provided by the hydropower plants. The measured geometries of the tailraces were also available from the hydropower plants. Montoya Ramírez et al. (2016) then compared hydraulic performance data from HK turbine manufacturers with the flow velocity and water depth present in the tailrace to determine if the installation was feasible. Because the study was intended to satisfy a preliminary evaluation of feasibility, no validation or error analysis of the generated data was conducted (Montoya Ramírez et al. 2016).

Nordino (2016) and Nhabetse et al. (2017) employed similar methods to generate VDCs for the Maputo River, Mozambique and Umbeluzi River, Mozambique, respectively, from which potential HK energy could be calculated. To generate the VDCs, five years of historical velocity data was used, and the flow velocities of the rivers were compared to the required design velocities of five HK turbines. This, and consideration of the required channel depths for the turbines, constituted the feasibility analysis of the study, and potential HK was calculated for both rivers from the VDC.

Holanda et al. (2017) studied the HK potential in the Tocantins River in Brazil. Discharge data were available for the location from 2007 to 2014 and bathymetry data were provided by the Eletronorte/Eletrobras Company who collected it in September 2004. Three discharge conditions were considered in the analysis: maximum, minimum, and mean. For simulation of the velocity, a 2D longitudinal-transverse hydrodynamic model and the Saint-Venant equation were used. Power was calculated using the kinetic instantaneous power equation. Validation of the model results was completed using ADCP field measurements conducted in 2012 and 2013. The comparison resulted in an average velocity error of $8.77 \%$ and a maximum error in the dataset of $22.00 \%$ (Holanda et al. 2017).

In a study conducted by Saupi et al. (2018) on the Batang Belleh River in Malaysia, regression equations were generated to estimate both water level and velocity at an ungauged location. To develop the regression equations, the Pearson Correlation Analysis techniques were used to determine the variables' correlation strengths, optimize parameters, and determine best fit. The regression models were validated against water level and water velocity data collected during different time periods than those used to generate the regression models. Among linear, logarithmic, quadratic, cubic, and exponential regression model types, the most suitable model was selected based on the highest $R^{2}$ value. The regression was conducted between water level data at a gauge station and 120 days of water level data collected at the remote location as well as between water level and 105 samples of ADCP velocity data. To validate the regression equations, 90 days of water level data were used, and the 
velocity data used for the validation were measured from March 2015 to May 2015. The validation resulted in $R^{2}$ of $87.4 \%$ and $87.9 \%$ for the water level and water velocity respectively. Saupi et al. (2018) state that these regression equations can be used to generate water velocity time series for remote, type- $C$, unregulated rivers.

Lata-Garcia et al. (2018) conducted their study on the Guayas River in Ecuador where one discharge of $3500 \mathrm{~m}^{3} / \mathrm{s}$ was incorporated to find the best possible location for the turbine for maximum HK power extraction. The channel bathymetry was available, and the velocities used for validation in the study were provided by the Ecuadorian Navy over one year where measurements were taken three times per day. The model used to simulate the velocity profile at the area of interest was HEC-RAS. To calculate the potential HK power available, the HOMER simulation tool was used to estimate HK power with velocity and the turbine parameters as inputs. No validation results were presented in the paper (Lata-Garcia et al. 2018).

In a study conducted by Kasman et al. (2019) downstream of the Balambano hydropower plant on the Balambano River in Indonesia, a computational fluid dynamics simulation is used to develop ten years of daily flow fluctuation data and the associated average flow velocity to estimate the available HK power. Inputs to the simulation are the river bathymetry collected via echo sounding equipment and flow data from 2012 to 2017 provided by the hydropower plant. To validate the output of the simulation, point velocity measurements were taken in the river at two cross sections with each cross section divided into nine measurement points. The type and model of the equipment used to measure the velocity were not specified. The simulation's output was averaged and compared to the averaged measured velocity and resulted in errors of $2.9 \%$ and $0.6 \%$ for the two cross sections (Kasman et al. 2019).

Silva dos Santos et al. (2019) studied the HK potential on the Amazon River at two locations downstream of hydropower plants in Northern Brazil. Discharge data were available for 2014 and historical discharge-area (wet area) and discharge-velocity curves were provided by the hydropower plant management. The hydraulic geometry (HG) relationships were based on either 3 years or 25 years of data, depending on the location. Bathymetry studies were conducted and included the use of a multi-frequency echo sounder as well as an ADCP for velocity measurements. The length of the river segment studied was $5 \mathrm{~km}$ long with 61 measured cross sections at one location and 64 measured cross sections at the other. A numerical model was used for the simulation of velocity profiles at locations that were expected to have high velocities. Experimental results were compared against the numerical model velocity results. Average deviations were $11.0 \%$ and $13.2 \%$ for each location. The simulated velocities were used to calculate the HK potential, and the deviations found in the velocity results were not carried forward into the power calculations. Seasonal variability of discharge was accounted for by presenting monthly potential HK power results rather than a yearly total (Silva dos Santos et al. 2019).

Adeogun et al. (2020) and Ali et al. (2020) conducted similar studies where GIS techniques and the Soil and Water Assessment Tool (SWAT) model were employed to predict flow and hydrological parameters for estimation of HK energy. Adeogun et al. (2020) estimated HK potential on the Asa, the Awun, and the Oyun Rivers in Nigeria, whereas the Ali et al. (2020) study was conducted on the U-Tapao River in Thailand. HK power was estimated using the hydropower equation with flow and hydraulic head as inputs. Hydraulic head was calculated using the difference between the elevation, provided by digital elevation models (DEMs), at the beginning of the river segment to the end of the river segment. When validated, the SWAT model showed a Nash-Sutcliffe Efficiency (NSE) of 0.70 and an $R^{2}$ of 0.74 for Adeogun et al. (2020). The validation for the study conducted by Ali et al. (2020) resulted in an NSE of 0.65 and an $R^{2}$ of 0.68 .
There are many similarities present in the methods examined above as well as inconsistencies which is what the IEC standards are attempting to avoid. Primarily, a great majority of the methods utilize some variation of the kinetic instantaneous power equation shown below:

(1) $\quad P_{\mathrm{K}}=\frac{1}{2} \rho A v^{3}$

where $P_{K}$ is the potential HK power, $\rho$ is the density of the fluid, $A$ is the wetted area, and $v$ is the velocity. Some other variations include power density and the addition of the power coefficient (a variable that converts the HK power estimate from theoretical to technical), respectively:

$$
\begin{aligned}
& \text { (2) } P_{\mathrm{K}} / A=\frac{1}{2} \rho v^{3} \\
& \text { (3) } \quad P_{\mathrm{K}} / A=\frac{1}{2} \rho v^{3} C_{\mathrm{p}}
\end{aligned}
$$

where $P_{\mathrm{K}} / A$ is the power density and $C_{\mathrm{p}}$ is the power coefficient (Duvoy and Toniolo 2012). Overall, none of the studies investigated met the standards of the IEC; however, this is likely due to the time in which they were published. The studies were published from 2011 to 2020 and the IEC standards were published in 2019. The two most common aspects of the studies that did not meet the IEC standards were capturing the variability of flow and calibration and validation of the model used. For proper representation of the variability of discharge, either the discharge data used were not available for ten or more years, or when the proper amount of data were available, FDCs were not developed to characterize the variability of discharge. When the discharge data were not available for ten of more years, few studies attempted to simulate ten years of discharge data using numerical modelling to develop an FDC. However, most of the locations considered in the studies were either directly at a tailrace of a dam or on a river that was regulated. Therefore, inaccuracies caused by not properly considering the seasonal and annual variability of discharge may be less pronounced in these types of regulated watersheds or even in watersheds of a particular hydrology (e.g., glacially fed channels are generally less impacted by annual variability (Ashmore and Church 2011)). Most of the studies used some type of modelling to simulate velocity within the channel. It was found that there was insufficient calibration and (or) validation of most of the models, that the calibration and (or) validation of the models were not described in enough detail to assess if the methods were suitable, or that the measure of success in which the models predicted velocity was not consistent across the studies. However, for all of these findings, the IEC standards provide a solution.

\section{Regional hydrokinetic energy resource assessments}

Dissimilar from local HK assessments, there are no published standards, specifications, or rules-of-thumb for regional types of HK assessments (Table 2). This section will explore and evaluate seven regional HK assessments from 1980 to 2014 to discover similarities between the studies, evaluate the methodologies and accuracies of the assessments, and attempt to draw conclusions about what is needed (e.g., data requirements, techniques, standards, etc.) to improve such assessments.

The first known HK assessment of this type was completed by the UMA Group (1980) for the National Research Council (NRC) in 1980. The goal of the study was to evaluate the total amount of HK power potentially available in Canadian rivers and streams. The study was limited to the largest rivers in Canada with discharges greater than $450 \mathrm{~m}^{3} / \mathrm{s}$, velocities greater than $1.5 \mathrm{~m} / \mathrm{s}$, channel widths greater than $50 \mathrm{~m}$, and channel depths greater 
Table 2. Regional hydrokinetic energy resource assessments.

\begin{tabular}{|c|c|c|c|c|c|c|}
\hline $\begin{array}{l}\text { Study } \\
\#\end{array}$ & Authors & Assessment approach & $\begin{array}{l}\text { Flow variation } \\
\text { consideration }\end{array}$ & $\begin{array}{l}\text { Estimation } \\
\text { method(s) }\end{array}$ & $\begin{array}{l}\text { Error analysis } \\
\text { method(s) }\end{array}$ & Quantified error result(s) \\
\hline 1) & $\begin{array}{l}\text { UMA Group (1980) } \\
\text { for NRC }\end{array}$ & Hydrokinetic power & No information available & Manning's equation & $\begin{array}{l}\text { No information } \\
\text { available }\end{array}$ & No information available \\
\hline 2) & $\begin{array}{l}\text { Acres Consulting } \\
\text { Services Limited } \\
(1984)\end{array}$ & Hydropower & $\begin{array}{l}\text { Maximum, mean, } \\
\text { minimum }\end{array}$ & $\begin{array}{l}\text { Multiple regression technique for } \\
\text { development of characteristic } \\
\text { relationships of region using } \\
\text { turbinable curve }\end{array}$ & $R^{2}$ & $\begin{array}{l}0.81,0.66,0.44 \text { for } \\
\text { maximum, mean, and } \\
\text { minimum, respectively }\end{array}$ \\
\hline 3) & Miller et al. (1986) & Hydrokinetic power & No information available & $\begin{array}{l}\text { Relationships between (1) discharge } \\
\text { and drainage area and (2) drainage } \\
\text { area and distance upstream from } \\
\text { mouth of river and use of } \\
\text { Manning's equation }\end{array}$ & $\begin{array}{l}\text { No information } \\
\text { available }\end{array}$ & No information available \\
\hline 4) & USDOE (2004) & Hydropower & No information available & $\begin{array}{l}\text { Drainage area, precipitation, and } \\
\text { temperature relationships to } \\
\text { estimate discharge using GIS tools }\end{array}$ & $\begin{array}{l}\text { Standard error for } \\
\text { discharge and RMSE } \\
\text { for hydraulic head }\end{array}$ & $\begin{array}{l} \pm 9 \% \text { to } \pm 96 \% \text { for } \\
\text { discharge, } \pm 3 \mathrm{~m} \text { for } \\
\text { hydraulic head }\end{array}$ \\
\hline 5) & $\begin{array}{l}\text { Kerr Wood Leidal } \\
\text { Associates (2008) }\end{array}$ & Hydropower & $\begin{array}{l}\text { Normal year, low- } \\
\text { discharge year, and a } \\
\text { high demand period }\end{array}$ & Hydropower assessment model & $\begin{array}{l}\text { No information } \\
\text { available }\end{array}$ & No information available \\
\hline 6) & $\begin{array}{l}\text { Jacobson (2012) for } \\
\text { EPRI }\end{array}$ & $\begin{array}{l}\text { Hydrokinetic power } \\
\text { and hydropower }\end{array}$ & $\begin{array}{l}5,25,50,75 \text {, and } \\
95 \text { percentiles }\end{array}$ & $\begin{array}{l}\text { HEC-RAS model and application of } \\
\text { estimated recovery factor }\end{array}$ & Percent deviation & $\begin{array}{l}\text { 77\% average deviation } \\
\text { for discharge between } \\
\text { estimated and gauge } \\
\text { station }\end{array}$ \\
\hline 7) & $\begin{array}{l}\text { NRC or the National } \\
\text { Academies (National } \\
\text { Research Council } \\
\text { 2013) }\end{array}$ & \multicolumn{5}{|c|}{ N/A, critique of Jacobson (2012) for EPRI } \\
\hline 8) & $\begin{array}{l}\text { Jakimavičius et al. } \\
\text { (2014) }\end{array}$ & Hydropower & Average multiannual & Hydraulic geometry approach & $\begin{array}{l}\text { Average relative error } \\
\text { of depth, width, and } \\
\text { velocity }\end{array}$ & $\begin{array}{l}14.0 \%, 17.9 \% \text {, and } 19.0 \% \\
\text { for depth, width, and } \\
\text { velocity, respectively }\end{array}$ \\
\hline 9) & $\begin{array}{l}\text { Jenkinson and Bomhof } \\
\text { (2014) }\end{array}$ & $\begin{array}{l}\text { Hydrokinetic power } \\
\text { and hydropower }\end{array}$ & 17-point FDC & $\begin{array}{l}\text { Multiple linear regression coupled } \\
\text { with canonical correlation } \\
\text { analysis and hydraulic geometry } \\
\text { approach }\end{array}$ & $\begin{array}{l}\text { Monte Carlo technique } \\
\text { used to determine } \\
\text { confidence } \\
\text { percentages in the } \\
\text { results }\end{array}$ & $\begin{array}{l}97.5 \% \text { confidence in } \\
433 \mathrm{GW} \text { hydropower } \\
\text { estimation and } 97.5 \% \\
\text { confidence in } 29 \mathrm{GW} \\
\text { hydrokinetic power } \\
\text { estimate }\end{array}$ \\
\hline 10) & Cruz et al. (2020) & Hydrokinetic power & Daily average & $\begin{array}{l}\text { Numerical model to estimate daily } \\
\text { average cross-sectional velocity }\end{array}$ & Average error & $\begin{array}{l}3.07 \% \text { and } 3.13 \% \text { for flow } \\
\text { and velocity, respectively }\end{array}$ \\
\hline
\end{tabular}


than $3 \mathrm{~m}$. The study was also limited to reaches for which there were 20 or more years of gauged data. Manning's equation was used for discharge velocity estimation in this case. Limited information is available on the actual techniques used in this assessment. Geographic information system (GIS) techniques were limited at the time (UMA Group 1980).

The next HK assessment of this type was conducted in 1984 by Acres Consulting Services Limited (1984). The intent of this Canadawide study was to decide whether additional funds should be invested to further investigate specific sites. This study divided Canada into 11 regions with similar climatological and physiographic characteristics, within which data from between 11 to 23 gauging stations and the characteristics of the areas were used to develop hydrologic relationships. The hydrologic relationships, called turbinable curves, characterized the dependence of the turbinable discharge (the flow that can be passed through a turbine at a particular design discharge) on the design discharge in each of the eleven regions. Physiographic characteristics were determined from 1:250 000 and 1:500 000 scale maps, and the following characteristics were considered in the regional analysis from various government maps: drainage age, basin perimeter, on-channel lake area, off-channel lake area, swamp area, mean annual runoff, mean annual temperature, longitude. A multiple regression technique was used to develop the relationships between characteristics of the regions and the turbinable curve fitting variables. The following equation is the regression model of the turbinable flow curve used for all 11 regions:

$$
Q_{T}=\phi+\theta Q_{D}+\alpha\left(Q_{D}\right)^{2}+\beta\left(Q_{D}\right)^{3}+\gamma\left(Q_{D}\right)^{4}+\kappa\left(Q_{D}\right)^{5}
$$

where $\phi, \beta, \gamma$, and $\kappa$ are described with the following equations:

$$
\begin{aligned}
& \phi=0 \\
& \beta=\frac{C^{2}(Z-6 \alpha)-12 C \theta+20}{2 C^{3}} \\
& \gamma=\frac{C^{2}(3 \alpha-Z)+8 C \theta-15}{C^{4}} \\
& \kappa=\frac{C^{2}(Z-2 \alpha)-6 C \theta+12}{2 C^{5}}
\end{aligned}
$$

The best curves from the regression analysis were chosen based on statistical (i.e., $R^{2}$ values) and physical significance, and the prior five-degree polynomial equations were fit to the curves. As shown by eqs. 4 to 8 , only $Z, C, \theta$, and $\alpha$ were to be determined for each region to develop the turbinable curves. These values depend on the aforementioned physiographic characteristics of the regions. The intent of this study's technique was to be able to estimate potential hydropower, using the following equation, rather than equations eq. 1 or eq. 2 :

$$
\text { (9) } \quad P_{\mathrm{H}}=\gamma \mathrm{HQ}
$$

where $P_{\mathrm{H}}$ is the potential hydropower, $\gamma$ is the fluid's specific weight, $H$ is the hydraulic head, and $Q$ is the river discharge. The errors in this method arise from the curve fitting method where $R^{2}$ ranged from $0.81,0.66$, and 0.44 for the maximum, mean, and minimum and from the physiographic and climatic data used in the assessment (Acres Consulting Services Limited 1984; Judge et al.1988).

Miller et al. (1986) conducted a study of potential HK power in the US in 1986 that employed the use of USGS gauged river data for discharge and topographic maps for channel slope and geometry. The study scope was limited to rivers with discharges greater than $113 \mathrm{~m}^{3} / \mathrm{s}$ and velocities greater than $1.3 \mathrm{~m} / \mathrm{s}$. Discharge was estimated at ungauged reaches by developing relationships between discharge and drainage area and then developing relationships between drainage area and the distance upstream from the mouth of the river. Similar to the UMA Group (1980) study, Manning's equation was used for velocity estimation. Limited information is available on this study, its accuracy, and its outcomes (Miller et al. 1986).

The US Department of Energy (DOE) (USDOE 2004) conducted an assessment for all available low-head hydropower in the US in 2004. The USDOE (2004) identified 18 unique regions and the following regression equation was used to estimate the mean annual discharge:

$$
\mathrm{Q}_{\mathrm{ma}}=\mathrm{e}^{a} \times A_{\mathrm{d}}{ }^{b} \times P_{\mathrm{ma}}{ }^{c} \times \mathrm{T}_{\mathrm{ma}}{ }^{d}
$$

where $Q_{m a}$ is the mean annual discharge, $A_{\mathrm{d}}$ is the drainage area, $P_{\text {ma }}$ is the mean annual precipitation, $T_{\text {ma }}$ is the mean annual temperature, and $a, b, c$, and $d$ are specific exponents calibrated to the unique 18 regions. To the authors' knowledge, this was the first type of this assessment that made use of GIS tools and DEMs to estimate hydropower. Hydraulic head was calculated using the elevation difference between the two points on either end of the stream segment in consideration. An equation similar to eq. 9 was used to calculate the hydropower of the stream segments, and the utilized hydropower that was extracted at the time (i.e., from hydroelectric dams already in existence) was subtracted from the total calculated hydropower. This yielded the result of available power potential. The study also categorized river segments into the following power and technology classes, based on the available power and hydraulic head: high head/high power, low head/high power, and high head/low power. As for the approximated error in the final calculated values, standard errors were propagated through the discharge estimates, to the individual stream power estimates, and finally to the total power estimate. Standard errors of the discharge estimates for each region varied from $\pm 9 \%$ to $\pm 96 \%$, depending on the region (Lower Colorado had the highest error); therefore, the USDOE (2004) stated that the uncertainties in the final power estimates were at least these values. Error was also recognized to result from the elevation data used to estimate hydraulic head. It was calculated that the root mean square error (RMSE) of the hydraulic head of each reach was $\pm 3 \mathrm{~m}$ (USDOE 2004).

Kerr Wood Leidal Associates (2008) developed the Rapid Hydropower Assessment Model (RHAM) for a regional assessment of small hydropower in British Columbia (BC), Canada. The RHAM model is GIS based and requires DEMs and hydrology data as input to calculate potential hydropower using an equation similar to eq. 9. The DEMs used in the study were provided by Natural Resources Canada (NRCan) and the hydrology data were provided by the BC Ministry of Environment. Seasonal variability of discharge was accounted for by considering a "normal" year, a "lowdischarge" year, and a "high demand period" to indicate how much the power source could be relied upon (Monk et al. 2009). A total of 8200 feasible project sites were identified across $\mathrm{BC}$ using the following selection criteria: discharge between 0.1 and $200 \mathrm{~m}^{3} / \mathrm{s}$, hydraulic head between 30 and $1000 \mathrm{~m}$, in-stream power greater than or equal to $500 \mathrm{~kW}$, and a set of practical selection criteria (e.g., park boundaries, protected fish habitats, etc.). The model was validated against the Water Survey of Canada discharge measurements; however, the results of this validation and the associated uncertainty in the power estimates were not provided. The model also calculated the capital cost of extracting HK power at each location using the best route to the accessible roads, transmission lines, etc. which were optimized by RHAM (Monk et al. 2009; Kerr Wood Leidal Associates 2008).

The Electric Power Research Institute (EPRI) (Jacobson 2012) was commissioned by the US DOE to provide an estimate of total riverine $\mathrm{HK}$ in the US and the resulting report was published in 2012. The study predicted two estimates of HK power: theoretically available power and technically available power. The theoretically 
available power was calculated similarly to the hydropower eq. 4 and the technically available power was calculated similarly to the HK power eq. 1 in addition to utilizing a recovery factor. For the theoretically available power, data were taken from the NHDPlus database, which is a GIS database containing discharge and channel slope information for river segments. Only the largest US rivers were used in the assessment initially, with the constraint of discharges greater than $283 \mathrm{~m}^{3} / \mathrm{s}$. The assessment was then expanded to rivers between $28.3 \mathrm{~m}^{3} / \mathrm{s}$ to $283 \mathrm{~m}^{3} / \mathrm{s}$ (1000 cfs to $10000 \mathrm{cfs}$ ). The report does not specify what type of discharge this is (i.e., mean annual discharge, 25 percentile discharge, etc.). The HEC-RAS model was employed to simulate average velocity at five different discharges: 5, 25, 50, 75, and 95 percentiles. A V-shaped channel was assumed when using the HEC-RAS model, and the effects of introducing the turbine into the river were considered in the HEC-RAS model. The recovery factor applied to calculate the technically available power was derived from the following data at five gauged sites: minimum required water velocity and depth during low discharge, device efficiency, and discharge statistics. Rivers with hydroelectric dams were excluded from the analysis at this point. From the analysis, it was found that the recovery factor decreased with increasing discharge. Application of the recovery factor decreased the theoretically available HK power of $1381 \mathrm{TWh} /$ year to the technically available HK power of $119.9 \mathrm{TWh} / \mathrm{year}$. A section of the report was dedicated to explaining and quantifying the uncertainty in the final results. Uncertainties were propagated from the slope and discharge data in the theoretical power result. The NHDPlus database used for slope values was compared to an alternative source (Google Earth or Wikipedia), and the comparison showed small uncertainties when considering the slope of the entire river. However, when smaller segments were analyzed, larger uncertainties were present. Discharge data in the NHDPlus database was compared to USGS discharges, and it was concluded that the differences contributed little to the overall uncertainty in the final power estimates. Uncertainties in the technical estimates were the result of assuming a V-shaped channel and a normalized flow distribution curve based solely on discharge statistics at one location on the Mississippi River. Uncertainties or deviations were represented either by $\%$ deviation or by $R^{2}$. A sensitivity analysis was also completed to determine the influence of various factors on the recovery factor (Jacobson 2012).

In 2013, the National Research Council (NRC) of the National Academies (National Research Council 2013) published an evaluation of the ERPI's assessment and associated recommendations for improving such assessments in the future. To begin, the NRC Assessment Committee created the conceptual framework of the difference between a theoretical resource, a technical resource, and a practical resource. This differentiation is also seen in the IEC standards where theoretical resource assessments are concerned with the idealized amount of HK power that can be extracted with all factors outside of the available energy resource not considered; technical resource assessments consider the limitations of HK power extraction technology; and practical resource assessments take into account the real-world societal, environmental, economic constraints (IEC 2019). The NRC argued that the EPRI (Jacobson 2012) study did not put proper emphasis on the practical resource aspect of the project, because the practical estimate would better represent realistic constraints to HK technology development and deployment. The NRC also presented a strong reservation to providing a single-number HK power estimate for the whole nation or for a large geographic region. The reason for this is that it does not lead to a realistic discussion when comparing HK power to other energy options, as it is usually intended to do. Additionally, because of the high level of uncertainty in the assessment, the resulting value obtained is not defensible. Another critique of the EPRI (Jacobson 2012) study was that the all-encompassing project proposed by the US DOE to estimate all marine and HK power in the US was split into five groups with little coordination and consistency among them in terms of methodology, validation, and deliverables. The third criticism was that not enough emphasis was put upon the device installation feedback on the environment in the analysis, as well as lack of or inconsistent validation and quantification of uncertainties in the estimates. Because the EPRI (Jacobson 2012) assessment also attempted to estimate technically available power, the NRC recommended to focus the analysis on locations that were most likely to provide most of the potential HK power and improve the assessment there, and to employ a two- or three-dimensional model to evaluate the turbine's effect on the river environment and discharge. Finally, the NRC recommended a stronger consideration of statistical variation of river discharge by utilizing discharge statistics for each segment. The NRC also recognized that modelling the river's discharge is complex and difficult when a turbine is introduced (National Research Council 2013).

Jakimavičius et al. (2014) conducted a large-scale study on 282 small and medium sized rivers in Lithuania where equations similar to those of hydraulic geometry (see eqs. 16-20 in Section 4) were used and he equation parameters were estimated to estimate channel geometry and flow velocity. The equations parameters were estimated using hydromorphological equation exponents compiled by Gailiušis et al. (2001). Using the estimates of velocity and water depth obtained via the equations, the channels available for energy extraction were filtered using depth and velocity constraints of greater than $0.5 \mathrm{~m}$ and greater than $0.4 \mathrm{~m} / \mathrm{s}$, respectively. This reduced the number of channels considered in the assessment to 41 . HK energy was calculated using the hydropower eq. 9 with the hydraulic head being the change in surface elevation over the river segment and the flow being the average multiannual discharge. The velocity, depth, and width equations used to constrain the number of channels used in the assessment were validated against data of 14 channels of various sizes which were not used in the original generation of the equations. The validation resulted in average relative errors of $14.0 \%, 17.9 \%$, and $19.0 \%$ for depth, width, and velocity, respectively (Jakimavičius et al. 2014).

To the authors' knowledge, one of the most recent extensive HK power assessments was completed by Jenkinson and Bomhof (2014) for the National Research Council (NRC) of Canada in 2014. This study utilized a regionalization approach to estimate discharge statistics for all river segments in Canada - gauged and ungauged - that could be analyzed. To begin, the drainage basins for each river segment in consideration were delineated using Voronoi tessellation. Then, to estimate discharge, the regionalization approach used was multiple linear regression coupled with canonical correlation analysis. This method was used under the assumption that streams across Canada in watersheds of similar physiographic characteristics would behave similarly. For example, the method would assume watersheds with particular ratios of landcover classes would behave hydrologically similarly to those with similar ratios. Discharge data were obtained from the Water Survey of Canada. The outputs of the regionalization were 17-point evenly distributed FDC for each stream segment. HG principles and another regionalization were used to estimate width and depth of river segments along each point of the FDC. The Water Survey of Canada - Measurement Database provided the channel geometry data for the analysis. Uncertainty was quantified using a Monte Carlo technique that represented the uncertainty with a distribution of discharges that corresponded with the distribution of the discharge estimate's uncertainty. Both the theoretical hydropower and the HK power were calculated in their analysis using the following two equations:

$$
\text { (11) } \quad P_{\mathrm{H}}=\gamma \mathrm{H} \int_{0}^{1} Q(f) \mathrm{d} f
$$




$$
P_{\mathrm{K}}=\gamma \operatorname{Ln}^{2} \int_{0}^{1} \frac{Q(f)^{3}}{w(f)^{2} d(f)^{2}[2 d(f)+w(f)]^{4 / 3}} \mathrm{~d} f
$$

where $L$ is the length of the river segment, $n$ is the Manning's roughness coefficient, and $Q(f), w(f)$, and $d(f)$ are the river discharge, flow width, and flow depth corresponding to the flow frequency, $f$, respectively. Equation 12 was derived using eq. 1 and Manning's equation. However, if this method were to be used in the future, the following equation should be used, as an error exists in eq. 12 where the wetted perimeter was used instead of the hydraulic radius for $R$.

$$
P_{\mathrm{K}}=\gamma \operatorname{Ln}^{2} \int_{0}^{1} \frac{Q(f)^{3}[2 d(f)+w(f)]^{4 / 3}}{[w(f) d(f)]^{8 / 3}} \mathrm{~d} f
$$

The resulting theoretical HK estimates for the Jenkinson and Bomhof (2014) study were $711 \mathrm{GW}$ with $97.5 \%$ confidence that at least $433 \mathrm{GW}$ was available for hydropower and $343 \mathrm{GW}$ with 97.5\% confidence that at least $29 \mathrm{GW}$ was available for HK power. The study, however, contained limitations. Uncertainties were properly considered in the final results, but this led to a wide range of possible values and ultimately showcased the imprecision in the data and regional analysis methods. The analysis was also not able to include the far north of Canada because of data limitations. Digital elevation model (DEM) resolution was limited at the time of analysis; thus, the river segment slope was calculated using elevation at the beginning and end points of the segment. This method of assuming a uniform slope would not have captured non-uniform elevation drops caused by falls, rapids, rocks, etc. Additionally, the HG method of estimating channel width and depth could not capture abnormalities in channel shape. This is of particular interest as channel constrictions could cause favorable conditions for high velocity and high HK potential. Finally, validation with data collected via a field campaign was performed for this assessment (Jenkinson and Bomhof 2014).

Cruz et al. (2020) developed a numerical model called the flowvelocity model that estimates daily average velocity and distribution of velocity across a transect of the channel using flow data. This study estimated the HK potential of all rivers in the Amazon Basin. To calibrate the model, parameters were optimized so that the simulated flow rate compared to the observed flow rate contained less than $10 \%$ relative error. The output of the model is velocity isolines across the cross section of interest. Validation was conducted with observed flows and velocities at three gauging stations. The validation resulted in average errors of $3.07 \%$ and $3.13 \%$ for the flow and the velocity, respectively. This study took the Betz limit (i.e., $C_{\mathrm{p}}=0.593$ ) and a more conservative $C_{\mathrm{p}}$ of 0.25 , recommended by Vermaak et al. (2014), into consideration when calculating estimates of HK potential (Cruz et al. 2020).

As shown in the progression of the HK assessments from 1980 to 2020 , it seems that the methods used to estimate HK power on the regional have become more complex with increasing understanding of the factors that affect the amount of HK power available. For example, models were utilized more often as the influence of two- and three-dimensional flow was understood, and discharge statistics were employed in the later studies as non-stationary climate was considered. It is difficult to conclude for certain, as documentation was scarce for some studies, but it appears that the consideration of variability of discharge increased gradually, with the first studies not taking it into consideration; the next generation of studies considering low, mean, and high discharges; and the later generation of studies utilizing a FDC or daily flow data to characterize the discharge variability. Also, data processing techniques changed as computational power increased, allowing for the use of complex numerical modelling and GIS techniques. In addition to the tools for HK assessments becoming more sophisticated, the resolution, amount, and quality of the data available for the assessments increased. Even now, DEM data are of higher resolution in some areas of Canada (i.e., Arctic and New Brunswick) than it was during Jenkinson and Bomhof's (2014) assessment. Documentation and reporting of the techniques used in the assessments also seems to have improved as time went on, with the most recent studies not only being publicly available for evaluation, but also the content and explanation in the reports was of higher quality. As far as evaluation of the results of the HK assessments, the procedures for validation and quantification of uncertainty were not consistent. Development of standard approaches for validation and uncertainty assessment would improve regional HK assessments. Providing a singular, comparable measure of the success of the method would improve these types of studies, as the most suitable and accurate methodology could be chosen to be employed in the future. Finally, as the NRC (2013) suggested in their evaluation of the EPRI's (Jacobson 2012) report, more emphasis could be placed on practical and technical availability of HK potential, rather than theoretical potential, as those two types of assessments would provide more value to the field of HK power evaluation. However, this is not to say that theoretical assessments should not be completed in the future. In the Jenkinson and Bomhof (2014) assessment, only theoretical HK potential was considered; however, the data and techniques used in the assessment and the scope of the study were novel at the time. Therefore, until the methodology and data required for these types of regional assessments are common enough to be standardized (as with local assessments), conducting regional theoretical assessments of HK potential are useful and essential.

As shown in local HK power studies in Section 2, sometimes sufficient discharge, bathymetry, or velocity data are not available for the location of interest to be able to calculate HK power from eq. 1 or eq. 2 . This issue is amplified when regional assessments are attempted. For example, the required velocity data are rarely already available at the location of interest or at the resolution required without a field-testing campaign. As per the IEC standards, even if numerical modelling is employed to simulate the velocity profile, two cross sections of velocity are required for validation. These data are not usually available in regional studies. Additionally, when attempting to estimate HK power at a regional scale, generally all rivers in the region are considered for analysis to detect the optimal reaches for HK power extraction. Rarely will all rivers and streams be properly gauged within a region, let alone contain ten or more years of discharge data. As per the IEC standards, the ten years of required discharge data can be simulated through modelling, but the data must be validated with one year of discharge data. The one year of discharge data may not be available for regional assessments, if one wishes to consider the HK potential of all reaches within a region. Because of time and expense constraints, accurate bathymetry data cannot be obtained via field measurements. As such, methods to estimate the bathymetry must be utilized to assess HK power in regional studies. If the locations of interest within the assessment region have depth and width measurements, a channel shape can be assumed (e.g., parabolic, trapezoidal, rectangular, etc.), and an approximate bathymetry can be obtained. However, reaches within the regional assessment may not have width or depth measurements, and they must be obtained or estimated through other means. Even if the data and methods are available to model the discharge, velocity, or bathymetry of the reaches within the regional assessment region, computational requirements may limit the use of those data and methods to local assessments. As such, a compromise must be struck between the amount and resolution of data available, computational requirements of manipulating the data, and the intent of the regional assessment. Generally, the purpose behind the regional assessment is not the same as the local. Regional studies are a type of pre-reconnaissance study to locate areas of interest that may contain promising HK potential to conduct a concentrated local assessment. Therefore, one must keep the methods of local 
assessments in mind but also do what is possible with the data and techniques available at the regional scale.

Limitations of regional types of HK assessments generally present themselves as some sort of threshold factor of the river for which HK estimates cannot be calculated or uncertainty limitations in the methods currently available. Regional assessments are always limited by some sort of threshold, and this threshold is determined by the amount, quality, and data available. For example, in Jenkinson and Bomhof's (2014) study, the far north of Canada could not be assessed because there were insufficient data to properly characterize the discharge in those regions. Additionally, the scopes of most of the earlier studies were limited by some threshold discharge, velocity, or channel geometry; however, information was not available for the reasoning behind these thresholds in the study reports, so it is not known if the thresholds were introduced due to data limitations, computational limitations, or practical reasons (e.g., low HK potential below some threshold discharge). Another current limitation of regional $\mathrm{HK}$ assessments is the uncertainty associated with the current methods. As shown by Jenkinson and Bomhof (2014) in their final hydropower and HK estimates and the associated uncertainties, great unreliability lies in the current methods of assessing HK potential to provide a single value of all HK power available in Canada. However, this uncertainty may be smaller for individual river reaches, which, as the NRC (2013) states, is the more relevant scale.

\section{New techniques/technologies}

For regional assessments, either an equation similar to eq. 1 can be used to calculate HK power or an equation similar to eq. 9 can be used to calculate hydropower. As both equations require different inputs, the section herein will cover new techniques or technologies that may yield more effective estimates of all of the equations' inputs. For hydropower estimation, the inputs are hydraulic head (i.e., slope or elevations) and river discharge. For HK power estimation, the inputs are velocity and cross-sectional area. If the HK power density equation is used (eq. 2), then only velocity is needed. To estimate velocity within the river, either the continuity equation or Manning's equation can be used, both of which are shown below, respectively:

$$
v=\frac{Q}{A}=\frac{Q}{w d}
$$

and

$$
v=k R^{2 / 3} S^{1 / 2} / n
$$

where $w$ is channel width, $d$ is channel depth, $k$ is the unit conversion factor ( $k=1$ for SI units and $k=1.49$ for English units), $R$ is the hydraulic radius (flow area divided by wetted perimeter), and $S$ is the slope (i.e., elevation and segment length). For either method of calculating velocity, width and depth are needed. For the continuity equation, river discharge is required and for Manning's equation, slope and roughness are required. These methods of calculating hydropower or HK power are purely theoretical and can be converted to technical or practical estimates by introducing a power coefficient or other factor to account for the turbine characteristics and by considering factors which may affect the feasibility of successful deployment (e.g., protected areas, proximity to communities or transmission lines, ease of access, etc.). As the conversion of theoretical HK power to technical or practical is circumstantial, only technologies and methods that may improve theoretical assessments will be discussed here.

\subsection{Discharge}

Recent developments in river discharge estimation methods and technologies are explored. Remote sensing methods of estimating discharge have been of particular interest, especially for rivers with no gauging stations and in remote areas where it would be expensive and restrictive to launch a field work campaign. These remote sensing techniques are not nearly accurate enough to replace a field campaign; therefore, use is dependent on the level of accuracy required for the assessment. Satellite techniques have gained much attention since the National Aeronautics and Space Administration (NASA) Surface Water and Ocean Topography (SWOT) mission was announced. The mission is set to launch in September 2021 (NASA 2020) and its applications reach far beyond river discharge estimation (Pavelsky 2019). Since the announcement of the data that will be available from the SWOT satellite mission, hydrologists have begun developing various methods to utilize the data to estimate river discharge, sometimes in combination with other data (i.e., gauged data from other areas, historical HG relationships, DEMs).

Gleason and Smith (2014) conducted a study in 2014 to test their proposed at-a-many-station HG (AMHG) method, when they realized a relationship existed between the coefficients and the exponents of traditional HG equations as will be explained below. Typical HG relationships are shown below:

$$
\begin{aligned}
& w=a Q^{b} \\
& d=c Q^{f} \\
& v=k Q^{m}
\end{aligned}
$$

where $a, c$, and $k$ are the calibrated coefficients and $b, f$, and $m$ are the calibrated exponents of the relationships, and:

$$
\begin{aligned}
& a c k=1 \\
& b+f+m=1
\end{aligned}
$$

HG relationship data from 88 USGS gauging stations across 6 rivers throughout the US were used to plot the exponents ( $b, f$, and $m$ ) against the coefficients $(a, c$, and $k$ ) of the relationships for each river, a strong log-linear relationship was found. For example, for a $428 \mathrm{~km}$ stretch of the Chattahoochee River that contained 13 gauging stations with available HG relationships, $b$ was plotted against $\log (a)$ and resulted in a linear relationship with an $R^{2}$ of 0.80 . Therefore, it was concluded that only one calibration parameter was needed for the width-discharge relationship at rivers where strong at-a-station hydraulic geometry existed. Gleason and Smith (2014) then compared the log-linear AMHG relationship between discharges and widths derived from HEC-RAS hydrodynamic model versus discharges derived from in situ measurements and widths extracted from LANDSAT data. This was completed across 3 different rivers for each scenario: Rio Grande, Mississippi, and Sacramento Rivers for the modelling approach and Athabasca, Mississippi, and Yangtze Rivers for the remote sensing approach. Gleason and Smith (2014) found strong conformities between the results from the in situ method versus the results from the remotely sensed width. Root mean squared error (RMSE) was used to quantify the errors in the proposed method. When comparing discharge measurements to the discharges estimated by the AMHG method, RMSEs were 23\%, 30\%, and $20 \%$ for the Mississippi, Athabasca, and Yangtze Rivers, respectively. When comparing the discharge estimations obtained from the HEC-RAS model versus discharge estimated by the AMHG method, RMSEs were 27\%, 26\%, and 1083\% for the Mississippi, Sacramento, and Rio Grande Rivers, respectively (Gleason and Smith 2014).

Liu et al. (2015) proposed a method in 2015 that utilized both the Soil and Water Assessment Tool (SWAT) hydrologic model and the XSECT hydraulic model in a looping algorithm to calibrate 
parameters and converge on the final estimates of water depth and discharge. Both optical imagery and altimetry data were used from ENVISAT and LANDSAT, respectively, to calibrate the parameters using water level and channel width. The method was evaluated on the Red River and, when the resulting discharge was compared to measured discharge, yielded $R^{2}$ values of 0.822 and 0.924 for daily and monthly discharge estimates. The analysis was expanded to the tributaries of the Red River and the resulting average $R^{2}$ of those discharge estimates was 0.809 over seven different gauge stations. As for water depth estimates, when compared to depth measurements, the average $R^{2}$ was 0.831 . Liu et al. (2015) found that the limitation to the success of this method was the resolution of available data.

Sichangi et al. (2016) conducted a study in 2016 on eight major rivers with channel widths greater than $800 \mathrm{~m}$ (Mississippi, Yangtze, Congo, Danube, Volga, Amazon, Lena, and Yenisey), and utilized satellite altimetry data, optical imagery, and DEMs to calibrate parameters in a modified Manning's equation to estimate discharge remotely. The altimetry data used was from multiple sources, including ERS-1, Topex/Poseidon, ERS-2, GEOSAT Follow-On, Jason-1, and ENVISAT and was used to create a water level time series. The optical imagery came from the Moderate Resolution Imaging Spectroradiometer (MODIS) satellite $(250 \mathrm{~m}$ resolution) and was used to determine channel width. MODIS images were chosen for their high temporal resolution to correlate the date of the altimetry data to the optical imagery. The average relative error associated with the channel widths derived from satellite imagery was $9.48 \%$, and the width uncertainty was less in smaller rivers (i.e., less discharge) compared to that of larger rivers. Sichangi et al. (2016) acknowledged that this error could be improved with using high spatial resolution satellite imagery. From the derived water level time series, estimated channel widths, and elevation data from the DEMs, the parameters in the modified Manning's equation were calibrated and the resulting discharges calculated had a Nash-Sutcliffe (NS) efficiency between 0.60 and 0.97 . Sichangi et al. (2016) also considered two different models: one which assumed that very large rivers had a constant width, where $Q$ was proportional to $d^{5 / 3}$, and another where $Q$ was proportional to $w \times d^{5 / 3}$. In general, the second model performed marginally better (NS of 0.60 versus 0.52 , relative RMSE (RRMSE) of $25.5 \%$ versus $27.8 \%$, relative error of $7.07 \%$ versus $7.57 \%$, and $R^{2}$ of 0.64 versus 0.56 for the Yangtze River) (Sichangi et al. 2016).

\subsection{Channel width and depth}

In past regional HK studies, channel dimensions were obtained either by direct measurements available through some regional or national database or by hydraulic geometry relationships and principles. However, these techniques can only be used if high quality, extensive data are available for a region. It is also important to note that, as well as spatial coverage, the data used for a regional HK assessment must have adequate temporal coverage. Because river discharge fluctuates, width-discharge and depthdischarge curves are required to properly characterize the variation in river conditions and, by association, the variation of potential HK power. New techniques, as shown above in the discharge section, have utilized remote sensing technologies to derive channel width to estimate discharge. Therefore, these same techniques could be promising for estimating channel width when calculating velocity using eq. 14 . On the other hand, methods of estimating channel depth from remote sensing techniques do exist but contain much error and uncertainty, as will be shown below. Sampson et al. (2015) made the argument that "river depth is the most difficult parameter to estimate as it is not yet possible to measure this remotely on large scales".

Generally, the method of determining channel width from optical imagery is split into two steps: water mask generation and derivation of widths from the mask. The first step is required to extract channel centerlines and widths using automated or semiautomated methods, which is desirable for regional assessments. What is meant by a water mask is generating an alternative image from the source image where the pixels are of only two values: water and non-water. This can also be called image segmentation. The steps required for successful creation of the water mask depend on the type of imagery that is available for manipulation. All imagery must first be orthorectified and geo-referenced to properly and accurately measure channel width (Ansari et al. 2017). The amount of noise, unwanted objects (e.g., clouds or other bodies of water), and required atmospheric correcting in the images must be considered in pre- and post-processing steps (Brisco et al. 2009; Elmi et al. 2016; Li and Sheng 2012; Ansari et al. 2017; Bolanos et al. 2016; O'Loughlin et al. 2013). Some pre-processing that can be applied to avoid inaccurate segmentation are initial thresholding, initial differentiation (e.g., employing DEMs to exclude areas of high slope), adjusting sharpness or blur, applying a Normalized Difference Vegetation Index, or applying a variety of other filters to optimize the difference between water and land pixel intensity (Ansari et al. 2017; O'Loughlin et al. 2013; Bolanos et al. 2016). Generally, images are also converted to greyscale and pixels are converted from intensity to decibel scale. After pre-processing, a segmentation method can be applied to differentiate the land pixels from the water pixels. The most common method of image segmentation is thresholding, where a threshold value, for which above or below pixels are designated as water, is chosen automatically. Some techniques that automatically select thresholds for this type of work are ISODATA, Mean, Maximum Entropy, Minimum Error, Moments, and Otsu (Ridler and Calvard 1978; Glasbey 1993; Kapur et al. 1985; Kittler and Illingworth 1986; Tsai 1985; Otsu 1979). Post-processing can also take place to refine the segmentation method's selections, such as disregarding lakes or glaciers.

After the water mask has been generated, the channel widths can be extracted using channel centerlines that are generally also generated as an intermediate step. The most common algorithm used to derive channel widths, at least in North America, is RivWidth (Pavelsky and Smith 2008; Allen and Pavelsky 2015; Durand et al. 2010; Allen et al. 2013; Miller et al. 2014; Pavelsky et al. 2015). The software was developed by Pavelsky and Smith (2008) and requires two input images to calculate channel widths at set intervals: the binary image with mid-channel land (e.g., sand bars or islands) included as land pixels and another binary image with mid-channel land not differentiated from the water it is surrounded by. However, O'Loughlin et al. (2013) argued that RivWidth created overlapping cross-sections where the channel turned at a sharp angle, and this introduced error into the channel widths. Other methods exist to derive channels widths, such as the methods by Sofia et al. (2015), O'Loughlin et al. (2013), and Yamazaki et al. (2014). Sofia et al. (2015) calculated channel width from a $1 \mathrm{~m}$ resolution light detection and ranging (LiDAR) digital terrain model (DTM) using a quantile-quantile plot statistical approach. Bankfull width is assumed to be where the Q-Q plot deviates from normality. This method was used to calculate reach-averaged width; however, the approach may not be sufficient to capture sudden constrictions in the channel. As mentioned before, O'Loughlin et al. (2013) had criticisms of RivWidth and, to correct the overlapping cross sections, employed a semiautomated method of developing orthogonals in HEC-GeoRAS to manually correct the errors. Yamazaki et al. (2014) used an existing dataset of water polygons called the Shuttle Radar Topography Mission Water Body Data to extract channel width using an algorithm that determined the centerline using the bank pixels and generated the discharge direction to the centerline. To work with the dataset, the method also required an algorithm to fill gaps in the water polygons. Using this method, Yamazaki et al. (2014) developed the Global Width Dataset for Large Rivers between $60^{\circ} \mathrm{N}$ and $60^{\circ} \mathrm{S}$. 
As mentioned previously, compared to channel width, channel depth estimation via remote sensing methods is more difficult and contains more uncertainty. The feasibility of utilizing the methods that will be mentioned depend on the type of data available across the region of interest (e.g., optical imagery versus altimetry data), the resolution of the available data, and the study location itself. As with channel width estimation, depth estimation generally consists of two steps: obtaining a water surface elevation dataset that is generated from altimetry or DEMs and estimating the channel depth using the water level time series and the proposed method. The method of depth estimation by Liu et al. (2015), mentioned previously in the discharge section, used a looping algorithm with two models - XSECT and SWAT to optimize parameters and converge on discharge and channel depth estimates. This method used water level time series from altimetry data and channel widths derived from optical imagery. The technique performed fairly well with an average $R^{2}$ of 0.831 when comparing derived channel depths to measured depths. Durand et al. (2014) utilized an algorithm based on Manning's equation to estimate channel depth and discharge using a pixel grid of synthetic SWOT measurements. The simulated water surface elevation data, intended to represent future SWOT data, was generated from an instrument measurement model and the hydrodynamic model LISFLOOD-FP. The purpose of Durand et al.'s (2014) study was to prepare a method of deriving channel depth and discharge from SWOT data before the SWOT data became available. This method required good temporal coverage of data; however, it can be argued that all channel depth estimation methods would require good temporal coverage of data for accurate estimates. Schaperow et al. (2019) proposed a method that built off of Mersel et al.'s (2013) work where water level data and channel width were essentially extrapolated to a zero water level condition using a number of relationships. The relationships proposed by Mersel et al. (2013) were linear and slope break and the relationships proposed by Schaperow et al. (2019) were non-linear and non-linear slope break. Better results were observed when more data coverage was available at different discharge conditions (i.e., capturing many different high and low discharges). The method resulted in a relative error of $-3.1 \%$ for non-linear slope break and $-7.1 \%$ for non-linear (Schaperow et al. 2019). Tourian et al. (2017) employed a method where, instead of extrapolating to a zero water level condition, a modified Manning's equation was used and the Gauss-Helmert Model (Helmert 1872) was applied. This method resulted in an estimate of the channel depth and the associated error when the parameters were converged upon in the iterative algorithm used, and the resulting average RRMSE was 10\% (Tourian et al. 2017). Again, success of the method depended on coverage and availability of the source data (Tourian et al. 2017). In general, for successful estimate of channel depth from remote sensing methods, good temporal coverage of available data are needed. However, to support regional HK assessments, the type of data (i.e., altimetry or elevation), the resolution of the data, and the amount of data needed are not currently available. In the future, the NASA SWOT mission may fill these needs and make estimation of channel depth from space possible.

\subsection{Channel slope}

To improve estimates of channel slope to support more accurate calculations of hydropower using eq. 9, new methods that require higher resolution DEMs or DTMs could be employed. In Canada particularly, with new data generation initiatives being launched nationally, provincially, and privately, a $1 \mathrm{~m}$ resolution LiDAR DTM is available in New Brunswick and $2 \mathrm{~m}$ digital surface models (DSMs) are available in the Canadian Arctic (north of $60^{\circ} \mathrm{N}$ ) via ArcticDEM. With these types of high resolution DTMs or DSMs, the channel can be represented as a number of elevation changes, rather than one elevation change between the points of interest and averaging the slope across that length (Allen et al. 2013). Allen et al. (2013) employed such a method which stretched DEMs and assigned an elevation to each centerline pixel along a meandering river using a $90 \mathrm{~m}$ resolution DEM and $5 \mathrm{~m}$ resolution optical imagery. They found that the represented channel profile more closely resembled the GPS field measurements, and the gradient was corrected by $-12.6 \%$ when employing this method compared to a traditional method of gradients only from DEMs (Allen et al. 2013).

\subsection{Roughness}

The flow resistance coefficient (e.g., Manning's roughness $n$ in eqs. 2-9) is usually assumed to be a constant value in regional HK studies (e.g., Jenkinson and Bomhof (2014)). To improve the estimation of regional roughness values, regionalized relationships between roughness and other measurable factors - discharge, slope, surficial geology, channel bed substrate D50 - could be explored, developed, and used to estimate bed and bank roughness. Two studies of natural river roughness were examined herein for relationships between roughness and the aforementioned factors. These studies were by Barnes (1967) for US rivers and by Hicks and Mason (1991) for New Zealand rivers. From the Barnes (1967) dataset, a relationship was found to exist between slope and roughness for rivers located in the US Western Cordillera with an $R^{2}$ of 0.694 . This suggests that a site-specific roughness estimate can be assigned to a river reach if the appropriate data are available and a strong relationship between roughness and other measurable factors can be identified. However, no other significant relationships were found between roughness and other measurable factors in the Barnes (1967) and the Hicks and Mason (1991) data. Thus, in future regional HK assessments, roughness will likely continue to be assigned a constant mean or typical value in areas of poor or no relationships between roughness and other factors.

\subsection{Other possible methods}

Other available data could possibly be utilized for these types of regional HK assessments, depending on the data available in the region. For example, d'Auteuil et al. (2019) explored the relationship between open water on rivers during winter and high velocity conditions using satellite imagery and field measurement campaigns. The idea was that if high velocity, and therefore high potential HK power, could be located using winter imagery, project developers could use that information to invest more into a particular location (d'Auteuil et al. 2019). However, as it seems, this method could not be used to estimate the amount of HK power available, only that the location has the potential for extractable HK power. Also available in Canada is NRCan's CanVec dataset which contains polygons for locations of rocks, rapids, falls, and other hydro obstacles within river channels where high velocities are more likely to exist. This dataset could possibly be used to focus HK assessments to reduce computational limitations. For example, computing channel gradient for all rivers in an entire country would be exceedingly computationally expensive, but if channel gradients were to be calculated only at the reaches for which a hydro obstacle occurs, the data would be more manageable. Also available through the NRCan's CanVec database are waterbody extent polygons which could be used for either preliminary or final determination of channel width, depending on the accuracy of the polygons' representation of channel shape. Other types of useful datasets could be available nationally or regionally for various nations around the world to aid in conducting these types of $\mathrm{HK}$ assessments.

\section{Review and research needs}

When comparing the methods used to complete local HK assessments to regional assessments, one finds that local methods cannot be replicated in regional studies and must be modified to suit computational and data limitations, particularly in the utilization of models. The discharge, bathymetry or stage, 
and velocity measurement data required for the IEC standards are not available at the regional scale if one desires to consider and estimate the HK potential in all rivers. Therefore, in the past, regional assessments have been limited to gauged river segments (UMA Group 1980; Miller et al. 1986; Kerr Wood Leidal Associates 2008; Monk et al. 2009; Jacobson 2012). However, newer techniques have allowed for estimation of ungauged river characteristics using techniques such as regionalization and discharge modelling (Jenkinson and Bomhof 2014; USDOE 2004). To combat the lack of data related to channel dimensions, and therefore mean velocity, authors of regional assessments have sometimes relied on the calculation of hydropower rather than HK power because the data were readily available (i.e., DEMs and discharge data).

To improve HK assessments, there are many steps that can be taken. For local assessments, researchers should follow the specifications set out by the IEC (2019) and only deviate when necessary with reasoning given. For regional assessments, the steps and ideology behind the IEC (2019) standards should be followed as closely as possible, but methods will be needed to generate the required data. To improve regional HK studies, uncertainty or error analysis should be more consistent and consideration should be taken towards the technical and practical applications of the generated data. The following aspects should always be considered in, if not introduced into the methodology of, regional assessments: discharge statistics, implications of complex flow, and climate change impacts. To improve these assessments, documentation should become more standardized, and as new data become available from various initiatives (e.g., SWOT, LiDAR DTMs, altimetry data, new satellite missions, etc.), assessments should be revisited to improve previous estimates.

The use of remote sensing techniques for aiding in these types of assessments should be thoroughly investigated. The capabilities of SWOT data, as well as other high resolution satellite products, should be tested to estimate hydrokinetic energy when it becomes available for research efforts. In particular, the methods used by Durand et al. (2014), Elmi et al. (2016), Tourian et al. (2017), and Schaperow et al. (2019), which were used to estimate channel geometry (depth and width) and discharge, are attractive to use for hydrokinetic energy estimation. With increased quantity and resolution of remotely sensed data, the aforementioned techniques, particularly the estimation of channel depth and discharge, will become more feasible and the accuracy of the results will improve. In addition to newly available remotely sensed data and techniques, alternative datasets available for the study region could be considered for their use in regional HK assessments. These datasets could possibly concentrate efforts in the assessment to areas of higher likelihood of high HK potential or feasibility, or even aid in preliminary or final determination of channel features to guide identification of optimal HK installation locations.

\section{Conclusions}

HK power extraction could provide a promising future for alternative electricity generation to facilitate the transition from fossil fuel sources in Canada and around the world. Regional theoretical, technical, and practical HK assessments are essential for understanding the feasibility of extracting and relying on this type of electricity in the future, as well as providing data to developers. To complete these assessments, a general trend involving the transition of manually manipulating relatively small amounts of available data to utilizing GIS, statistical, and modelling techniques to manipulate and generate new data (e.g., discharge, velocity, channel dimensions, etc.). In the most recent regional HK assessments, the influence of discharge variation was appropriately considered, and the uncertainty of the estimation method was properly characterized, which is an improvement from previous studies and consistent with the IEC standards (Jenkinson and
Bomhof 2014; IEC 2019). Since this study, hydrologists have explored utilizing remote sensing methods to estimate channel features with varying success. The most successful methods are concerned with estimating channel width, whereas estimation of channel depth is still difficult to accomplish from space. As the resolution and quantity of the available remotely sensed data increases, the presented methods will become more feasible to accurately estimate channel features. Other available hydrology data for the region of interest should be explored thoroughly for use in the regional assessments. Because the type and amount of data are inconsistent across regions (e.g., in Canada, LiDAR is only available north of $60^{\circ} \mathrm{N}$ and in New Brunswick), the methods of regional HK assessments may never be as uniform as local assessments. However, as new methods are developed to estimate channel characteristics for regional HK assessments, the IEC standards for local HK assessments should be considered. For example, the influence of discharge variation, quantification of uncertainty or error, and possible utilization of models should always be considered in any type of HK assessment.

\section{Funding statement}

The authors would like to acknowledge that this work was funded in part by the Office of Energy Research and Development (OERD) of Natural Resources Canada and in part by National Research Council Canada.

\section{References}

Acres Consulting Services Limited. 1984. Hydrologic design methodologies for small-scale hydro at ungauged sites - phase i: Applications manual. Technical report. Environment Canada, Inland Waters Directorate.

Adeogun, A.G., Ganiyu, H.O., Ladokun, L.L., and Ibitoye, B.A. 2020. Evaluation of hydrokinetic energy potentials of selected rivers in Kwara state, Nigeria. Environmental Engineering Research, 25(3): 267-273. doi:10.4491/ eer.2018.028

Ali, F., Srisuwan, C., Techato, K., Bennui, A., Suepa, T., and Niammuad, D. 2020. Theoretical hydrokinetic power potential assessment of the U-Tapao river basin using GIS. Energies, 13(7): 1749. doi:10.3390/en13071749.

Allen, G.H., and Pavelsky, T.M. 2015. Patterns of river width and surface area revealed by the satellite-derived North American River Width data set. Geophysical Research Letters, 42: 395-402. doi:10.1002/2014GL062764.

Allen, G.H., Barnes, J.B., Pavelsky, T.M., and Kirby, E. 2013. Lithologic and tectonic controls on bedrock channel form at the northwest Himalayan front. Journal of Geophysical Research: Earth Surface, 118: 1806-1825. doi:10.1002/jgrf.20113.

Ansari, S., Rennie, C., Seidou, D., Malenchak, O.J., and Zare, S.G. 2017. Automated monitoring of river ice processes using shore-based imagery. Cold Regions Science and Technology, 142: 1-16. doi:10.1016/j.coldregions.2017.06.011.

Arango, M. 2011. Resource assessment and feasibility study for use of hydrokinetic turbines in the tailwaters of the Priest Rapids Project. A thesis submitted in partial fulfillment of the requirements for the degree of Master of Science in Mechanical Engineering, University of Washington.

Ashmore, P., and Church, M. 2011. The impact of climate change on rivers and river processes in Canada. Geological Survey of Canada Bulletin 555. Natural Resources Canada.

Barnes, H.H. 1967. Roughness characteristics of natural channels. Watersupply paper 1849. U.S. Geological Survey, Washington, DC.

Bolanos, S., Stiff, D., Brisco, B., and Pietroniro, A. 2016. Operational surface water detection and monitoring using Radarsat 2. Remote Sensing, 8: 285-303. doi:10.3390/rs8040285.

Brisco, B., Short, N., van der Sanden, J., Landry, R., and Raymond, D. 2009. A semi-automated tool for surface water mapping with RADARSAT-1. Canadian Journal of Remote Sensing, 35(4): 336-344. doi:10.5589/m09-025.

Cornett, A., and Faure, T. 2015. Assessment of hydrokinetic energy resources in the St Lawrence River and Estuary. National Research Council Canada, Ocean Coastal \& River Engineering, Ottawa, Ont.

Cruz, J.D.S., Blanco, C.J.C., and Brasil Junior, A.C.P. 2020. Flow-velocity model for hydrokinetic energy availability assessment in the Amazon. Acta Scientiarum - Technology, 42(1): e45703. doi:10.4025/actascitechnol. v42i1.45703.

d'Auteuil, S., Birjandi, A., Bibeau, E., Jordan, S., Soviak, J., and Friesen, D. 2019. Riverine hydrokinetic resource assessment using low cost winter imagery. Renewable and Sustainable Energy Reviews, 105: 293-300. doi:10.1016/j. rser.2019.01.057.

Durand, M., Rodríguez, E., Alsdorf, D.E., and Trigg, M. 2010. Estimating river depth from remote sensing swath interferometry measurements of river height, slope, and width. IEEE Journal of Selected Topics in Applied Earth 
Observations and Remote Sensing, 3(1): 20-31. doi:10.1109/JSTARS.2009. 2033453.

Durand, M., Neal, J., Rodriguez, E., Andreadis, K.M., Smith, L.C., and Yoon, Y. 2014. Estimating reach-averaged discharge for the River Severn from measurements of river water surface elevation and slope. Journal of Hydrology, 511: 92-104. doi:10.1016/j.jhydrol.2013.12.050.

Duvoy, P., and Toniolo, H. 2012. HYDROKAL: a module for in-stream hydro kinetic resource assessment. Computers \& Geosciences, 39: 171-181. doi:10.1016/j. cageo.2011.06.016.

Elmi, O., Tourian, M.J., and Sneeuw, N. 2016. Dynamic river masks from multi-temporal satellite imagery: an automatic algorithm using graph cuts optimization. Remote Sensing, 8: 1005-1037. doi:10.3390/rs8121005.

Environment and Climate Change Canada. 2016. Canada's mid-century longterm low-greenhouse gas development strategy. Cat. No. 978-0-660-06577-9. Government of Canada, Gatineau, Que.

Filizola, N., Edileuza, M., Armijos, E., and McGlynn, J.H. 2015. Preliminary analysis of potential for river hydrokinetic energy technologies in the Amazon basin. Technical Note IDB-TN-891. Inter-American Development Bank, Washington, DC. doi:10.18235/0000222.

Gailiušis, B., Jablonskis, J., and Kovalenkovienè, M. 2001. The Lithuanian rivers. Hydrography and runoff. Kaunas Lietuvos Energetikos Institutas. [In Lithuanian]

Glasbey, C.A. 1993. An analysis of histogram-based thresholding algorithms. CVGIP: Graphical Models and Image Processing, 55: 532-537. doi:10.1006/ cgip.1993.1040.

Gleason, C., and Smith, L. 2014. Toward global mapping of river discharge using satellite images and at-many-stations hydraulic geometry. Proceedings of the National Academy of Sciences of the United States of America, 111(13): 4788-4791. doi:10.1073/pnas.1317606111.

Government of Canada. 2019. Coal phase-out: the powering past coal alliance. Available from https://www.canada.ca/en/services/environment/weather/ climatechange/canada-international-action/coal-phase-out.html.

Government of Canada. 2020a. Clean Growth Hub. Available from http:// www.ic.gc.ca/eic/site/099.nsf/eng/home.

Government of Canada. 2020b. The Low Carbon Economy Fund. Available from https://www.canada.ca/en/environment-climate-change/services/climatechange/low-carbon-economy-fund.html.

Helmert, F.R. 1872. Die Ausgleichungsrechnung nach der Methode der Kleinsten Quadrate: Mit Anwendungen auf die. BG Teubner, Leipzig, Germany.

Hicks, D.M., and Mason, P.D. 1991. Roughness characteristics of New Zealand rivers. National Institute of Water and Atmospheric Research Ltd., Christchurch, New Zealand.

Holanda, P.D.S., Blanco, C.J.C., Mesquita, A.L.A., Brasil Junior, A.C.P. de Figueiredo, N.M., Macêdo, E.N., and Secretan, Y. 2017. Assessment of hydrokinetic energy resources downstream of hydropower plants. Renewable Energy, 101: 1203-1214. doi:10.1016/j.renene.2016.10.011.

IEC. 2019. Marine energy - wave, tidal and other water current converters part 301: river energy resource assessment. IEC TS 62600-301:2019. International Electrotechnical Commission, Geneva, Switzerland.

IHO. 2020. IHO Standards for Hydrographic Surveys. 6th ed. IHO Publication No. 44. International Hydrographic Organization, Principauté de Monaco.

Jacobson, P. 2012. Assessment and mapping of the riverine hydrokinetic energy resource in the continental United States. Technical report. Electric Power Research Institute, Palo Alto, Calif.

Jakimavičius, D., Gailiušis, B., Šarauskienè, D., Jurgelènaitè, A., and MeilutytèLukauskiené, D. 2014. Assessment of the riverine hydrokinetic energy resources in Lithuania. Baltica, 27(2): 141-150. doi:10.5200/baltica.2014.27.23.

Jenkinson, R.W., and Bomhof, J. 2014. Assessment of Canada's hydrokinetic power potential: phase III resource estimation. Natural Resources Canada Ocean Coastal and River Engineering for Natural Resources Canada - Marine Energy Group.

Judge, D., Anderson, J., McClennan, B., and Park, E. 1988. Hydrologic design methodologies for prefeasibility studies of small-scale hydro at ungauged sites. Canadian Journal of Civil Engineering, 15(3): 289-298. doi:10.1139/188-044.

Kalnacs, A., Kalnacs, J., Mutule, A., and Persis, U. 2014. Methods for estimation of the riverflow potential for hydrokinetic power generation. Latvian Journal of Physics and Technical Sciences, 51: 3-10. doi:10.2478/lpts-2014-0008.

Kapur, J.N., Sahoo, P.K., and Wong, A.K. 1985. A new method of gray-level picture thresholding using the entropy of the histogram. Computer Vision, Graphics and Image Processing, 29: 273-285. doi:10.1016/0734189X(85)90125-2.

Kasman, Hantoro, R., and Eptanto, I.L. 2019. Study potency of hydrokinetic energy in discharge Balambano hydro electric power plant. AIP Conference Proceedings, 2088: 030015. doi:10.1063/1.5095320.

Kerr Wood Leidal Associates. 2008. Computer modelling for water - finding run-of-river hydroelectricty potential in B.C. Available from https://www. canadianconsultingengineer.com/features/computer-modelling-for-water/ [Accessed 27 July 2020].

Kittler, J., and Illingworth, J. 1986. Minimum error thresholding. Pattern Recognition, 19(1): 41-47. doi:10.1016/0031-3203(86)90030-0.

Lata-Garcia, J., Jurado, F., Fernandez-Ramirez, L., and Sanchez-Sainz, H. 2018. Optimal hydrokinetic turbine location and techno-economic analysis of a hybrid system based on photovoltaic/hydrokinetic/hydrogen/battery. Energy, 159: 611-620. doi:10.1016/j.energy.2018.06.183.
Li, J., and Sheng, Y. 2012. An automated scheme for glacial lake dynamics mapping using Landsat imagery and digital elevation models: a case study in the Himalayas. International Journal of Remote Sensing, 33(16): 5194-5213. doi:10.1080/01431161.2012.657370.

Liu, G., Schwartz, F., Tseng, K.-H., and Shum, C.K. 2015. Discharge and waterdepth estimates for ungauged rivers: combining hydrologic, hydraulic, and inverse modeling with stage and water-area measurements from satellites. Water Resources Research, 51: 6017-6035. doi:10.1002/2015WR016971.

Mersel, M.K., Smith, L.C., Andreadis, K.M., and Durand, M.T. 2013. Estimation of river depth from remotely sensed hydraulic relationships. Water Resources Research, 49: 3165-3179. doi:10.1002/wrcr.20176.

Miller, G., Franceschi, J., Lese, W., and Rico, J. 1986. The allocation of kinetic hydro energy conversion systems (KHECS) in USA drainage basins: regional resource and potential power. NYUDAS 86-151, final report.

Miller, Z.F., Pavelsky, T.M., and Allen, G.H. 2014. Quantifying river form variations in the Mississippi Basin using remotely sensed imagery. Hydrology and Earth System Sciences, 18: 4883-4895. doi:10.5194/hess-18-4883-2014.

Monk, R., Joyce, S., and Homenuke, M. 2009. Rapid hydropower assessment model: Identify hydroelectric sites using geographic information systems. In Proceedings of the Waterpower 16th 2009 Conference, Spokane, Wash., 2730 July 2009. Kerr Wood Leidal Associates Ltd., Vancouver, BC.

Montoya Ramírez, R.D., Cuervo, F.I., and Rico, C.A.M. 2016. Technical and financial valuation of hydrokinetic power in the discharge channels of large hydropower plants in Colombia: a case study. Renewable Energy, 99: 136-147. doi:10.1016/j.renene.2016.06.047.

NASA. 2020. Mission: overview. Available from https://swot.jpl.nasa.gov/mission.htm [Accessed 4 March 2020].

National Research Council. 2013. An evaluation of the U.S. Department of energy's marine and hydrokinetic resource assessments. The National Academies Press, Washington, DC. doi:10.17226/18278.

Natural Resources Canada. 2019. Clean energy for rural and remote communities: BioHeat, demonstration \& deployment program streams. Available from https://www.nrcan.gc.ca/reducingdiesel.

Neary, V., Gunawan, B., Richmond, M., Durgesh, V., Polagye, B., Thomson, J., et al. 2011. Field measurements at river and tidal current sites for hydrokinetic energy development: best practices manual. Oak Ridge National Laboratory, Oak Ridge, Tenn.

Nhabetse, T., Cuamba, B., Kucel, S., and Mungoi, N. 2017. Assessment of hydrokinetic potential in the Umbeluzi Basin, Mozambique. In Proceedings of the ISES Solar World Congress 2017 with IEA SHC Solar Heating and Cooling Conference, Abu Dhabi, UAE, 29 October-2 November 2017. pp. 1455-1466. doi:10.18086/swc.2017.23.04

Nordino, M.M. 2016. An assessment of hydrokinetic potential in the Maputo Basins, Mozambique. Masters thesis, Makerere University Institutional Repository, School of Engineering (SEng.) Collections.

O'Loughlin, F., Trigg, M.A., Schumann, G.J.-P., and Bates, P.D. 2013. Hydraulic characterization of the middle reach of the Congo River. Water Resources Research, 49: 5059-5070. doi:10.1002/wrcr.20398.

Otsu, N. 1979. A thresholding selection method from gray-level histograms. IEEE Transactions on Systems, Man, and Cybernetics, 9: 62-66. doi:10.1109/ TSMC.1979.4310076.

Pavelsky, T.M. 2019. Satellites reveal a new view of Earth's water from space. The Conversation 13 February 2019. Available from http://theconversation.com/ satellites-reveal-a-new-view-of-earths-water-from-space-109048 [Accessed 4 March 2020].

Pavelsky, T.M., and Smith, L.C. 2008. RivWidth: a software tool for the calculation of river widths from remotely sensed imagery. IEEE Geoscience and Remote Sensing Letters, 5(1): 70-73. doi:10.1109/LGRS.2007.908305.

Pavelsky, T.M., Allen, G.H., and Miller, Z.F. 2015. Spatial patterns of river width in the Yukon River Basin. In Remote Sensing of the Terrestrial Water Cycle. Geophysical Monograph 206. Edited by V. Lakshmi. John Wiley \& Sons, Inc. pp. 131-141.

Petrie, J., Diplas, P., Gutierrez, M., and Nam, S. 2014. Characterizing the mean flow field in rivers for resource and environmental impact assessments of hydrokinetic energy generation sites. Renewable Energy, 69: 393-401. doi:10.1016/j.renene.2014.03.064.

Punys, P., Adamonyte, I., Kvaraciejus, A., Martinaitis, G., Vyciene, E., and Kasiulis, E. 2015. Riverine hydrokinetic resource assessment. A case study of a lowland river in Lituania. Renewable and Sustainable Energy Reviews, 50: 643-652. doi:10.1016/j.rser.2015.04.155.

Ridler, T.W., and Calvard, S. 1978. Picture thresholding using an iterative selection method. IEEE Transactions on Systems, Man, and Cybernetics, 8: 630-632. doi:10.1109/TSMC.1978.4310039.

Sampson, C.C., Smith, A.M., Bates, P.D., Neal, J.C., Alfieri, L., and Freer, J.E. 2015. A high-resolution global flood hazard model. Water Resources Research, 51: 7358-7381. doi:10.1002/2015WR016954. PMID:27594719.

Silva dos Santos, I.F., Ramirez Camacho, R.G., Filho, G.L.T., Barkett Botan, A.C., and Amoeiro Vinent, B.A. 2019. Energy potential and economic analysis of hydrokinetic turbines implementation in rivers: an approach using numerical predictions (CFD) and experimental data. Renewable Energy, 143: 648662. doi:10.1016/j.renene.2019.05.018.

Saupi, A.F.M., Mailah, N.F., Radzi, M.A.M., Mohamad, K.B., Ahmad, S.Z., and Soh, A.C. 2018. An illustrated guide to estimation of water velocity in unregulated river for hydrokinetic performance analysis studies in East Malaysia. Water, 10(10): 1330. doi:10.3390/w10101330. 
Schaperow, J.R., Li, D., Margulis, S.A., and Lettenmaier, D.P. 2019. A curve-fitting method of estimating bathymetry from water surface height and width. Water Resources Research, 55: 4288-4303. doi:10.1029/2019WR024938.

Sichangi, A., Wang, L., Yang, K., Chen, D., Wang, Z., Li, X., et al. 2016. Estimating continental river basin discharges using multiple remote sensing data sets. Remote Sensing of Environment, 179: 36-53. doi:10.1016/j.rse.2016.03.019.

Silva dos Santos, I., Camacho, R., Filho, G., Botan, A., and Vincent, B. 2019. Energy potential and economic analysis of hydrokinetic turbines implementation in rivers: an approach using numerical predictions (CFD) and experimental data. Renewable Energy, 143: 648-662. doi:10.1016/j.renene.2019.05.018.

Sofia, G., Tarolli, P., Cazorzi, F., and Fontana, G.D. 2015. Downstream hydraulic geometry relationships: gathering reference reach-scale width values from LiDAR. Geomorphology, 250: 236-248. doi:10.1016/j.geomorph.2015.09.002.

Tourian, M.J., Elmi, O., Mohammadnejad, A., and Sneeuw, N. 2017. Estimating river depth from SWOT-type observables obtained by satellite altimetry and imagery. Water, 9: 753. doi:10.3390/w9100753.

Tsai, W.-H. 1985. Moment-preserving thresholding: a new approach. Computer Vision, Graphics and Image Processing, 29(3): 377-393. doi:10.1016/ 0734-189X(85)90133-1.
UMA Group. 1980. An evaluation of the kinetic energy of Canadian rivers \& estuaries. Technical Report. Canadian National Research Council - Canadian Hydraulics Centre.

USDOE. 2004. Water energy resources of the United States with emphasis on low head/low power resources. Technical Report DOE/ID-11111. U.S. Department of Energy Idaho Operations Office.

Vermaak, H.J., Kusakana, K., and Koko, S.P. 2014. Status of micro-hydrokinetic river technology in rural applications: a review of literature. Renewable and Sustainable Energy Reviews, 29: 625-633. doi:10.1016/j.rser.2013.08.066.

World Meteorological Organization. 2010. Manual on stream gauging (WMO 1044). World Meteorological Organization (WMO), Geneva, Switzerland.

Yamazaki, D., O’Loughlin, F., Trigg, M.A., Miller, Z.F., Pavelsky, T.M., and Bates, P.D. 2014. Development of the global width database for large rivers. Water Resources Research, 50: 3467-3480. doi:10.1002/2013WR014664.

Yuce, M.I., and Muratoglu, A. 2015. Hydrokinetic energy conversion systems: a technology status review. Renewable and Sustainable Energy Reviews, 43: 72-82. doi:10.1016/j.rser.2014.10.037. 